\title{
EFICACIA DEL PROCEDIMIENTO DE TUTELA LABORAL COMO PROTECCION CONTRA EL MOBBING EN CHILE
}

\author{
LuCía Planet SepúlvedA*
}

\begin{abstract}
RESUMEN: La "constitucionalización"l del derecho laboral ha permitido lograr un avance en la protección de los derechos fundamentales al interior de la empresa, tanto por la aplicación entre particulares de los derechos fundamentales ${ }^{2}$ como por la progresiva aparición de normas laborales que los resguardan. Pese a la falta de regulación en la legislación chilena sobre la figura del mobbing, o acoso psíquico laboral, la protección a los derechos fundamentales que se ven involucrados con esta contrariedad permite configurar cauces jurídicos para enfrentarla.

Las vías jurídicas típicas, antes de la reforma procesal laboral, se limitaban principalmente a acciones ordinarias indemnizatorias, al despido indirecto o a la acción de protección. Con la nueva reforma labora ${ }^{3}$ se instauró lo que viene a ser la gran vía para enfrentar el mobbing, pues contempla los avances recogidos por las nuevas doctrinas en torno a la protección de derechos inespecíficos. El presente trabajo pretende determinar si la utilización de este procedimiento será eficaz ${ }^{4}$ para que el trabajador acosado recupere el estado anterior al hostigamiento, con el resarcimiento de los perjuicios a los cuales se haya visto expuesto.
\end{abstract}

Palabras clave: Mobbing, acoso, derechos fundamentales, procedimiento de tutela, indicios.

ABSTRACT: The "constitutionalisation" of the labor law has allowed an advance in the protection of the fundamental rights inside the company, as much for the aplication between individuals of the fundamental rights, as for the progressive aparition of labor regulations that supports them. Even for the absence of regulation in the chilean legislation about the figure of mobbing or labor psychological abuse, the protection of the fundamental rights wich are involved in this contrariety, allows to configurate juridical ways to confront it.

The typical juridic ways, before the labor procedure reformation, were limitated principaly to ordinary indemnization actions, the indirect firing or the protection action. The new labor procedure reformation instaurated wich it is the great way to confornt the mobbing, because contemplates the advances taken by the new doctrines about the protection of unspecified rigths. The current paper pretends to determinate if the use of this procedure will be efficient for the abused worker to regain the state before the abuse, qith the compensation for the damages wich he has been exposed.

Key words: Mobbing, abuse, fundamental rights, tutelage procedure, indications.

\footnotetext{
* Abogada, Universidad de Chile. Diplomada en Derecho Laboral, Universidad de Chile. Defensora Laboral de la Región Metropolitana. Contacto: luciaplanet@yahoo.com

${ }^{1}$ Según Ugarte, "En este nuevo paradigma, la clave será considerar que las normas constitucionales tienen todas -sin distinción- plena eficacia vinculante, incluidas, especialmente, las que estipulan los derechos fundamentales de las personas (eficacia directa de la Constitución), y que, por tanto, son susceptibles de producir efectos jurídicos inmediatos, sin necesidad de mediación legal de ningún tipo", en: UGARTE CATALDO, José Luis, Tutela de Derechos fundamentales del trabajador, Editorial Legal Publishing, Santiago, 2009, p. 9.

${ }^{2} \mathrm{El}$ "efecto horizontal" de los derechos fundamentales se trata en el segundo apartado de este ensayo.

${ }^{3}$ Las leyes $\mathrm{N}^{\circ} 20.022,20.087$ y 20.252 publicadas en el Diario Oficial el 30 de mayo de 2005, el 3 de enero de 2006 y el 15 de febrero de 2008, respectivamente, introdujeron importantes modificaciones al Libro V del Código del Trabajo, referido a los Juzgados de Letras del Trabajo y de Cobranza Laboral y del Procedimiento.

${ }^{4}$ El concepto de eficacia se empleará en su sentido etimológico (del latín eficaz que tiene el poder de producir el efecto deseado), es decir, aquella que consiste en el logro del fin, objeto o meta para el cual fue previsto.
} 


\section{PREELIMINARES}

El Derecho Laboral se ha constituido como un derecho tutelar de orden público no por mero capricho, sino por las posiciones desiguales de las partes que conforman la relación laboral ${ }^{5}$. Sin subordinación no existe relación laboral ${ }^{6}$, y sin relación de poder no se mantiene vigente la subordinación. La relación de poder se ve plasmada en los poderes de mando, de reglamentación y el de disciplina ${ }^{7}$ que tiene el empleador ${ }^{8}$.

Estas particularidades de la relación de trabajo generan un escenario proclive a una eventual lesión de derechos fundamentales para con la parte más débil. La más mínima expresión de poder en manos equivocadas puede provocar consecuencias garrafales durante la jornada de trabajo del subordinado, que puede empeorar en tiempos de crisis económica9.

No parece adecuado suprimir las potestades que la legislación y doctrina laboral han reconocido al empleador para poder organizar su empresa, pero sí se torna necesario establecer límites claros respecto a su utilización ${ }^{10}$.

En ese contexto aparece como una necesidad cierta el precaver medios idóneos para amparar jurisdiccionalmente el exceso de los límites establecidos por el legislador para el empleador, cuyo traspaso implica la vulneración de los derechos fundamentales de los involucrados. Es en esta óptica donde las últimas modificaciones laborales significan un gran avance:

\footnotetext{
5 "El principio protector se refiere al criterio fundamental que oriente el derecho del trabajo ya que este, en lugar de inspirarse en un propósito de igualdad responde al objetivo de establecer un amparo preferente a una de las partes. El trabajador", en: PLA RODRIGUEZ, Américo, Curso de Derecho laboral, Ediciones Idea, Uruguay, 1991, p. 38.

${ }^{6} \mathrm{La}$ subordinación es un elemento constitutivo de la relación laboral establecido en el artículo $7^{\circ}$ del Código del Trabajo. Véanse los dictámenes ORD No 2524/141 de 23 de mayo de 1999 y No $1533 / 69$ del 13 de abril de 2004 .

7 "La porestad de dirección le permite al empleador ordenar el trabajo dentro de la empresa y se manifiesta en un conjunto de instrucciones y reglamentos dirigidos a los trabajadores en general", en: LIZAMA PORTAL, Luis y UGARTE CATAldo, José Luis, Nueva Ley de Acoso Sexual, primera edición, Editorial LexisNexis, Santiago, 2005, p. 29. Asimismo, la Dirección del Trabajo, en Dictamen ORD. No 2328/130, de 19 de julio de 2002, ha señalado que "Los poderes del empresario reconocen su fundamento último en la libertad de empresa y en el derecho de propiedad -artículos 19, No 21 y 24 de la Constitución, respectivamente-, garantías constitucionales, que apuntan a dotar al empresario, por una parte, del poder de iniciativa económica, y por otra, del ejercicio mismo de la actividad empresarial. Asimismo, al empresario le es reconocido el ejercicio de una serie de facultades o prerrogativas que tienen por objeto el logro del referido proyecto empresarial en lo que al ámbito laboral se refiere, y que responden a lo que genéricamente se denomina poder de dirección -comprendiendo en este concepto amplio tanto el poder de dirección strictu sensu como el disciplinario-, los que si bien encuentran, como se dijo, sustento en la garantía constitucional de la libertad de empresa y el derecho de propiedad en cuanto conforman un cúmulo de facultades organizativas para el empresario, se definen y concretizan en cuanto a su extensión y configuración en el contrato de trabajo -dichos poderes no pueden ejercerse más allá de la relación laboral y extenderse a la actividad extralaboral del trabajador-, a lo que debemos agregar la ley -será el legislador el que regule el ejercicio legítimo de este poder estableciendo normas mínimas irrenunciables, así como su uso no arbitrario".

${ }^{8}$ Es en este binomio de poder de dirección/subordinación en términos de Sergio Gamonal, donde se contextualiza la relación laboral.

9 Las autoridades han reconocido la importancia de enfrentar las implicancias laborales y sociales que se generan con las crisis económicas; al respecto, la ex ministra del Trabajo Claudia Serrano señaló "Estamos haciendo todos los esfuerzos para mantener la senda del crecimiento conciliando equidad social y trabajo decente para nuestra gente. Nuestro papel como Ministerio del Trabajo y Previsión Social exige una actitud de vigilancia constante de ello, de búsqueda de acuerdos, de generación de Diálogo Social como uno de los instrumentos para alcanzar los consensos y la paz social, especialmente en épocas de crisis económicas", en: Normas de OIT y Justicia Social, Santiago, 2009, p. 11.

${ }^{10}$ Límites claros se han establecido en las modificaciones a los artículos 2 y 5 del Código del Trabajo y en el establecimiento del nuevo procedimiento de tutela en el libro $\mathrm{V}$ del Código del Trabajo.
} 
"El gran aporte de la reforma laboral importa un avance para hacer ingresar en el horizonte cultural de los operadores del derecho, y más importante aún, de los propios actores laborales, el universo propio del lenguaje de lo derechos fundamentales, con ideas como la intimidad, la libertad de expresión o la dignidad personal, tan poco compatible, en ocasiones, con la concepción tradicional de la relación laboral como un vínculo que dota al empleador de un poder de mando y sujeta al trabajador a un estricto deber de obediencia, por una parte, y tan lejos de las ideas modernas de gestión de los recursos humanos y en general de eso que gráficamente se ha denominado 'la ética de los asuntos simbolizada por el mercado' que ha dominado el escenario americano durante casi tres décadas, por otra". ${ }^{11}$.

\section{EL FENÓMENO DEL $M O B B I N G$}

Ya en la década de los sesenta del siglo XX se observa el origen de la conceptualización del mobbing como fenómeno:

"un primer acercamiento se encuentra en estudios realizados por Konrad Lorenz (...) sobre la agresividad en el comportamiento animal ${ }^{12}$, especialmente en las ratas, y su reacción ante la inclusión en el clan de un animal que no pertenece a él o que, habiendo pertenecido, se le saca del mismo por un tiempo y luego se le vuelve a incorporar. Entre las observaciones realizadas por Lorenz, se advirtió que el clan ataca a este supuesto animal extraño con manifiesta agresividad"13.

En la década de los ochenta, el psicólogo alemán Heinz Leymann "describió y analizó los distintos comportamientos hostiles que se presentan en las organizaciones, particularmente en las relaciones laborales (...) así, describe una serie de conductas que producen una extrema incomodidad al sujeto acosado -trabajador- que lo puede llevar al total desequilibrio psíquico" ${ }^{14}$. Es el mismo Leymann el que acuñaría el término mobbing ${ }^{15}$ para describir este fenómeno.

Hoy en día la prensa nacional como internacional ${ }^{16}$ reconoce que se repite de forma cada vez más frecuente el fenómeno del mobbing. En el año 2001, el Parlamento Europeo emitió una resolución en la que identificaba la magnitud del fenómeno:

\footnotetext{
11 Ugarte Cataldo, José Luis, El Nuevo Derecho del Trabajo, primera edición, Editorial Universitaria, Santiago, Chile, 2004 , p. 129.

12 Citado por Abajo Olivares, Francisco Javier, Acoso psicológico en el ámbito laboral, LexisNexis-DePalma, Buenos Aires, 2004, pp. 15 y ss. Gamonal Contreras, Sergio; Prado LOPeZ, Pamela, El mobbing o acoso moral laboral, Editorial LexisNexis, Santiago, Chile, 2009 , p. 8.

13 Ibid. p. 8.

${ }^{14}$ Ibid. p. 9.

${ }^{15}$ Del término inglés mob, que en su acepción de verbo (to mob) significa acosar, asediar, atacar; en su acepción de sustantivo significa multitud, y en sentido peyorativo, significa mafia. Información disponible en <www.wordreference.com> [consulta 11 de enero de 2010$]$.

${ }^{16}$ Las páginas de internet <http://mobbingopinion.bpweb.net/> y <www.acosomoral.org> contienen una recopilación de noticias internacionales sobre mobbing.
} 
"considerando que un 8\% de los empleados de la Unión Europea, es decir, unos 12 millones de personas, afirman haber sido víctimas de acoso moral en el lugar de trabajo en el intervalo de los últimos 12 meses, según una encuesta realizada a 21.5000 trabajadores por la Fundación Europea para la Mejora de las Condiciones de Vida y Trabajo (con sede en Dublín), y que debemos partir de la base de una cifra de casos desconocidos considerablemente superior" ${ }^{17}$.

Las encuestas en Chile han reflejado que:

"en cuanto a autopercepción, la mayor parte de los trabajadores chilenos no sienten que se les respeta en su lugar de trabajo. Según encuestas del año 2002, efectuadas por el Centro de Estudios de la Realidad Contemporánea (Barómetro Cerc) el 69\% de las personas consideraba que los jefes no eran respetuosos en su trato, mientras que otra investigación del mismo organismo en 2005 develó que solo un $49 \%$ de las personas creían que los empleadores entregaba un trato digno a los empleados. La segunda Encuesta Nacional de Calidad de Vida y Salud del Ministerio de Salud, del 2006, reveló que 9,4\% de los hombres y 7,6\% de las mujeres habían sido afectados por situaciones de maltrato laboral (físico, psicológico o acoso sexual)"18.

Asimismo el número de fiscalizaciones que se solicitan a la Inspección del Trabajo por este ítem debería dar una pauta de las cifras al respecto.

\subsection{CONCEPTO}

Diversas disciplinas como la psicología, la etología y el derecho se han preocupado por definir el mobbing. Expresiones como acoso moral, acoso psíquico laboral, acoso psicológico, psicoterror, entre otros, se han utilizado para referirse a él.

El psicólogo español Iñaki Piñuel y Zabala define el mobbing como:

"un continuado y deliberado maltrato que se produce contra un trabajador por parte de otro u otros con vistas a someterlo, amilanarlo, eliminarlo o destruirlo psicológicamente. Por alguna razón la víctima suele ser alguien que se ha vuelto amenazante para quien la hostiga. Estas conductas de tipo objetivo y con una entidad real, se caracterizan por una variada gama de formas de hostigamientos recurrentes y habituales que sumen a la víctima en la indefensión psicológica. Quien las sufre siente que no puede escapar a ellas en la medida que no recibe la adecuada protección por parte de su organización y al mismo tiempo no puede dejar de ir a trabajar" 19 .

\footnotetext{
17 Parte de la Resolución A5-0283/2001 (2001/2339 (INI) disponible en: <www.acosomoral.org> [consulta 15 de enero de 2010].

${ }^{18}$ MAZZo ItUrRiaGA, Rodrigo, "De qué se habla: mobbing", Santiago, 2009, en: < http://www.bcn.cl/de-que-se-habla/ mobbing-acoso-chile> [consulta 15 de enero de 2010].

19 Piñuel Y Zabala, Iñaki, "El Mobbing aumenta entre los funcionarios", Madrid, 2008, disponible en: < http:// acosopsicologico.blogspot.com/2008_09_01_archive.html>[consulta 18 de enero de 2010].
} 


\section{Heinz Leymann precisa que el mobbing:}

"conlleva una comunicación hostil y desprovista de ética que es administrada en forma sistemática por uno o unos pocos individuos, principalmente contra un único individuo, quien, a consecuencia de ello, es arrojado a una situación de soledad e indefensión prolongada, a base de acciones de hostigamiento frecuentes y persistentes (definición estadística: al menos una vez por semana) y a lo largo de un prolongado período (definición estadística: al menos durante seis meses). Como consecuencia de la alta frecuencia y larga duración de estas conductas hostiles, tal maltrato se traduce en un enorme suplicio psicológico, psicosomático y social"20.

Marie-France Hirgoyen, psicoterapeuta francesa, lo ha definido como "toda conducta abusiva (gesto, palabra, comportamiento, actitud..) que atenta, por su repetición o sistematización, contra la dignidad o la integridad psíquica o física de la persona poniendo en peligro su empleo o degradando el ambiente de trabajo" 21 .

Y en el ámbito del derecho laboral, se ha conceptualizado el mobbing como:

"los actos de agresión, múltiples y reiterados en el tiempo, instigados o ejecutados por el empleador, sus representantes y/o por uno o más compañeros de trabajo, que tienen como consecuencia producir un ambiente laboral degradante y dañino para la víctima (...) se habla de acoso porque se trata de un comportamiento que se configura por agresiones múltiples y reiteradas en el tiempo (también resulta apropiado hablar de persecución u hostigamiento); es psíquico porque el blanco de los ataques es la psique o alma del acosado; y es laboral, porque aunque es posible verificarla en otros ámbitos de interacción social, la conducta se desarrolla preferentemente dentro de las organizaciones de trabajo" 22 .

Estudios internacionales han señalado que el mobbing puede tener consecuencias graves para la salud del individuo ${ }^{23}$, los síntomas pueden dividirse en aquellos de tipo psíquico y en aquellos de tipo fisiológico, "dependiendo de su intensidad y duración, el acoso psíquico provoca en la víctima diversos grados de perturbación anímica que van desde síntomas muy cercanos al estrés y a la depresión a daños permanentes en su estructura mental, además de una amplia variedad de trastornos psicosomáticos" 24 .

\footnotetext{
20 Citado por Gamonal Contreras, Sergio; Prado LÓpez, Pamela, El mobbing o acoso moral laboral, Editorial LexisNexis, Santiago, Chile, 2009, p. 8.

21 Citado por Gamonal Contreras, Sergio, Guidi Moggia, Caterina, Manual del Contrato de Trabajo, primera edición, Editorial Abeledo Perrot-LegalPublishing, Santiago, Chile, 2010, p. 222.

22 Palavecino CACeres, Claudio, "La Protección Contra el Acoso Psíquico Laboral en el Ordenamiento Jurídico Chileno", en: Revista de Derecho, Valdivia, [online]. 2004, Vol.17 [citado 2010-02-22], pp. 63-89. Disponible en: <http:// www.scielo.cl/scielo.php?script=sci_arttext \&pid=S0718-09502004000200003\&lng=es\&nrm=iso >. ISSN 0718-0950. doi: 10.4067/S0718-09502004000200003 [consulta 15 de enero de 2010].

23 Al respecto véase el Estudio de la Sociedad Valenciana de Medicina y Seguridad en el Trabajo, disponible en <wWw.symst.com>

${ }^{24}$ Palavecino Cáceres, Claudio, op. cit.
} 
Por otro lado, se ha advertido por la doctrina laboral que en las empresas en que existen grupos de trabajadores "que suelen caracterizarse por fuertes vínculos de solidaridad y simpatía entre sus componentes (...) las tasas de movilidad y de ausentismo son muy bajas, en tanto que alcanza elevados índices de productividad" 25 .

\subsection{MODALIDADES DE MOBBING}

En lo que dice relación con las formas en que se manifiesta el mobbing se suelen identificar tres categorías en base a quién es la víctima del acoso, a la repetición del hostigamiento en el tiempo, la cantidad de sujetos involucrados y a la generalización de la conducta en la empresa. Sin perjuicio de lo anterior, se han ido identificando nuevas formas que tienen que ver con el contexto específico en que se desenvuelve el mobbing.

\section{a) Mobbing vertical $y$ mobbing horizontal26}

Lo determinante en esta clasificación es quién es el sujeto activo o pasivo de la conducta del hostigamiento 27 .

El sujeto activo del mobbing puede ser cualquier persona, sin importar su cargo ni ubicación jerárquica dentro de a empresa. Si el sujeto activo que produce el hostigamiento es el empleador -situación más común-, se trata de un mobbing vertical descendente.

Si por el contrario, el sujeto activo es el subordinado que produce un hostigamiento a su superior jerárquico, se trata de un mobbing ascendente, situación más escasa por la precisa relación de subordinación que existe en la relación de trabajo y la dependencia del trabajador de sus autoridades para la mantención de su fuente de trabajo.

Si el hostigamiento proviene de un compañero de trabajo, estamos frente al mobbing horizontal, ya que el sujeto activo es un $\operatorname{par}^{28}$.

Puede darse una mixtura entre estos dos tipos de mobbing, lo que es conocido como mobbing mixto, el que tiene la particularidad de comenzar como mobbing horizontal entre compañeros de trabajo, pero que una vez que las autoridades toman conocimiento de esta conducta "no adoptan ninguna medida para que la situación se solucione"29.

\footnotetext{
${ }^{25}$ Canabellas de TORres, Guillermo; AlCala Zamora y CASTIllo, Luis, Tratado de Politica Laboral y Social, Tomo II, tercera edición, Editorial Heliasta, Buenos Aires, 1964 , p. 215.

${ }^{26}$ Los mismos fallos judiciales han reconocido esta clasificación, "Con relación a los protagonistas del mobbing se ha dicho: Se debe destacar que el mobbing puede ser ejercido en forma vertical y horizontal. El primero de ellos es el que ejecuta el empleador o un superior jerárquico contra el trabajador y mediante el cual se pretende el retiro del obrero de la empresa, por resultar su presencia incómoda"; en: sentencia del Tribunal Superior de Justicia de la Provincia de Río Negro, el 6 de abril de 2005, en causa Expediente No 17.505/02-STJ Caratulado Dufey, Rosario Beatriz c/ entretenimiento Patagonia s.a. s/sumario s/ inaplicabilidad de ley, disponible en: http://www.caq.org.ar/shop/detallenot.asp?notid=700 27 Similar clasificación respecto del acoso sexual se desprende de la redacción final del arrículo $2^{\circ}$ del Código del Trabajo, incorporada por la Ley $\mathrm{N}^{\circ} 20.005$.

${ }^{28}$ Las motivaciones de esta modalidad del mobbing consistirían en "que la víctima sea una persona recta, honrada, o con gran capacidad de trabajo, o que se destaque por su carácter autónomo o tenga una vida personal o familiar satisfactoria, o sea popular en la organización (...) todo lo cual lo transforma en foco de envidias y rivaliciad por parte de sujetos acosadores", en: Gamonal Contreras, Sergio; Guidi Moggia, Caterina, Manual... (n. 21), p. 222.

29 Gamonal Contreras, Sergio, Prado López, Pamela, El mobbing... (n. 20), p. 24.
} 


\section{b) Quick mobbing $o$ mobbing propiamente tal}

Dentro de los requisitos que se encuentran asentados por las disciplinas que han investigado el mobbing -propiamente tal-, se halla la sistematización en el tiempo de la conducta hostigadora. Se ha entendido por diversos autores que la periodicidad de la conducta y la duración en el tiempo -como media seis meses- sería un requisito esencial para configurar el mobbing, "El acosador, el hostigador, ataca a su víctima de manera recurrente y sistemática. Se trata de una víctima elegida, seleccionada. No se trata de un conflicto aislado, ni de un incidente anecdótico o anodino. Se trata de una tarea sistemática que, a juicio de Leymann, debe llevarse al menos una vez por semana y durante un tiempo prolongado -al menos seis meses-"30.

Al respecto, Sergio Gamonal ha precisado que "existe una extensa discusión sobre los plazos mínimos para entender que se configura un mobbing. En efecto, se ha destacado que seis meses sería la regla general pero que, excepcionalmente, podrán bastar tres meses si los ataques son muy frecuentes (diarios) e intensos"31. Es en este último caso cuando estaríamos frente a la figura del quick mobbing.

\section{c) Mobbing singular o plural}

Tal como su nombre lo indica, se tratará de un mobbing singular cuando el sujeto activo que realice el hostigamiento sea una sola persona, y será plural, cuando el sujeto acosador esté constituido por un grupo de personas.

\section{d) Mobbing institucional y mobbing estratégico}

Gamonal y Guidi se refieren al mobbing institucional como aquel "referido al manejo de personal y forma organizativa de la empresa que implica condiciones de trabajo estresantes" 32 . Por otro lado, el acoso estratégico "se plantea como un medio utilizado por la empresa para liberarse de un trabajador que ya no quiere mantener: de tal forma que estamos ante una verdadera decisión empresarial que utiliza el mobbing como una herramienta eficaz con el fin de propender a que el trabajador renuncie al no tolerar el ambiente hostil en que se desempeña" 33 .

\section{e) Mobbing asociado a contextos especificos}

La finalidad que puede tener el sujeto acosador para efectuar un acoso a otra persona, puede tener diversas motivaciones. Si un trabajador se afilia a un sindicato, toma una licencia médica o pide fiscalizaciones a la Inspección del Trabajo para denunciar alguna conducta infractora de su empleador, puede generar una animadversión que derive en mobbing. Si este se provoca por las diferencias de origen étnico, etario, entre otras, estaremos en presencia de un mobbing discriminatorio ${ }^{34}$. Asimismo, el acoso sexual puede

\footnotetext{
${ }^{30}$ Abajo Olivares, Francisco Javier, op. cit., p. 9.

31 Gamonal Contreras, Sergio; Guidi Moggia, Caterina, Manual... (n. 21), p. 222.

32 Gamonal Contreras, Sergio; Guidi Moggia, Caterina, Manual... (n. 21), p. 223.

33 Gamonal Contreras, Sergio; Prado López, Pamela, El mobbing... (n. 20), p. 26.

${ }^{34} \mathrm{La}$ Constitución Política prohíbe cualquier discriminación que no se base en la capacidad e idoneidad personal, sin perjuicio de excepciones legales que consagra.
} 
ir acompañado del hostigamiento que caracteriza al mobbing, caso en el cual estaremos en presencia de un mobbing sexual ${ }^{35}$.

Otra situación que puede gatillar que se produzca mobbing, es el estado de embarazo de las mujeres que trabajan en la empresa, en este caso:

"no se busca la destrucción de la víctima de forma directa, sino que a pesar de que lo anterior se consiga igualmente, lo que se busca más inmediata y directamente es mostrar un ejemplo de lo que le puede pasar a "la que se atreva a... quedarse embarazada. Es un castigo ejemplar que sirva de aviso para otras mujeres que observan lo que le ocurre a la víctima. (...) En nuestro último estudio Cisneros XI (Véase la web www.liderazgozero.com) establece que el pasado año en España: 18\% de las trabajadoras denuncian que en su organización se producen presiones contra las mujeres por causa de su maternidad (...) Estos agresores, que a veces incluso son otras mujeres, eso sí, en posición de superioridad jerárquica, suelen ser personas que frecuentemente abusan y se prevalen de su posición de poder jerárquico formal y que usan su poder de tipo informal en la organización para desplegar sus frustraciones, compensar sus complejos o dar rienda suelta a todas y cada una de sus tendencias más agresivas y antisociales" 36 .

\section{f) Doble mobbing}

Esta figura dice relación con los efectos que puede producir el mobbing en la vida familiar de la víctima:

"se produce cuando los problemas familiares surgen con posterioridad al acoso moral laboral, y conlleva un proceso que puede sintetizarse de la siguiente forma: etapa de empatía y comprensión, etapa de desinterés (por el agotamiento y exasperación de la familia frente a la situación del acosado, debido a que este vuelca en ella, en forma reiterada, la negatividad de su situación laboral); etapa de hostilidad (la familia ve amenazada su integridad y serenidad por la víctima y efectúa una especie de contraataque...)"37.

\subsection{REQUISITOS}

No cualquier hostigamiento es capaz de configurar la figura del mobbing. Se ha entendido que "el acoso laboral o psicológico se presenta como un proceso de paulatino desarrollo, que solapadamente y en forma permanente va socavando la fortaleza especialmente psíquica del trabajador afectado" 38 .

\footnotetext{
35 Sin perjuicio de lo anterior, el acoso sexual es un fenómeno distinto al mobbing, en el cual su sola presentación basta para configurar el acoso sexual. En Chile, la Ley $\mathrm{N}^{\circ} 20.005$ contempló medidas preventivas y disciplinarias en contra de este ilícito laboral. El dictamen ORD N $1133 / 36$ de 21 de marzo de 2005 se ha referido a esta temática.

36 PIÑUEl y ZaBALA, Iñaki, "El Mobbing aumenta entre los funcionarios", Madrid, 2008, disponible en: <http:// acosopsicologico.blogspot.com/2008_09_01_archive.html>

37 Gamonal Contreras, Sergio; GUIDI MOGgia, Caterina, Manual... (n. 21), p. 223.

38 LANATA FUenzalida, Gabriela, Contrato individual de trabajo, tercera edición, Editorial LegalPublishing, Santiago, 2009 , p. 73.
} 
Leymann describió más de 45 conductas constitutivas de mobbing $g^{39}$, por ejemplo, el hecho de atacar a una persona verbalmente, de amenazarlo, de aislarlo de su entorno laboral, de asignarle tareas inútiles, exponerlo a trabajos de alto riesgo o demasiado exigentes, cambiarle frecuentemente sus tareas y responsabilidades, no se le habla, se hace burla de sus creencias o aptitudes.

Sin embargo, para que se configure una situación mobbing deben darse ciertos elementos, a saber:

a) Que se trate de un hostigamiento sistemático y continuo en el tiempo ${ }^{40}$ : se requiere periodicidad en la conducta y que esta persista en un tiempo de seis meses, a menos que se trate de un quick mobbing o que la legislación expresamente señale que se tipificará como mobbing una sola conducta de gravedad suficiente ${ }^{41}$.

Con todo, el mobbing es un proceso que se desarrollará en diversas etapas ${ }^{42}$ : desde la óptica de la empresa: a) la fase del conflicto o de incidentes críticos, caracterizada por el conflicto no resuelto entre personas; b) la fase del acoso o estigmatización, en la cual se desarrolla el hostigamiento por parte del sujeto acosador aunque la víctima apenas lo perciba, y se genera desánimo, pérdida de seguridad y confianza y bajo rendimiento en la víctima; c) la fase de intervención desde la empresa, cuando esta percibe el acoso y que puede concretarse en traslados o incluso el despido de uno de los intervinientes, aunque se trate de la misma víctima, y d) fase de solicitud de ayuda especializada externa, en el que el diagnóstico rara vez hace la debida conexión con las verdaderas causas del problema; desde el punto de vista de la víctima, esta entrará en una fase inicial de acoso en el que paulatinamente irá perdiendo la seguridad, posteriormente el conflicto "se abrirá" y los efectos del hostigamiento se hacen más palpables, y finalmente en la fase del "escape" donde la víctima tratará de evadir su realidad laboral a través de la presentación de licencias médicas o derechamente de su renuncia al mismo.

Por tanto un hecho aislado de hostigamiento difícilmente podrá configurar un mobbing, como tampoco malas condiciones laborales, la mala gestión del personal o el estrés laboral ${ }^{43}$.

b) Se desarrolla en una relación de trabajo, donde existen diferencias de poder formal o informal entre los acosadores $y$ la victima.

c) Debe existir una finalidad por parte del sujeto activo:

"A veces, lo que busca el acosador es, simple y llanamente, satisfacer un apetito sádico; o bien compensar sentimientos de inferioridad, de envidia o de miedo. Pero, de ordinario, el acosador quiere algo más. Desea que la víctima se someta a su designio -que cambie de actitud, que "entre en vereda" o, en defecto de lo anterior, que abandone su puesto de trabajo. También el acoso puede tener la finalidad de

\footnotetext{
39 Véase las 45 conductas en el sitio web: < http://www.acosomoral.org/leyman $45 . \mathrm{htm}>$

40 MAZzo ITURRIAGA, Rodrigo, "De qué se habla: mobbing", Santiago, 2009, en: < http://www.bcn.cl/de-que-se-habla/ mobbing-acoso-chiles.

41 Por ejemplo en la legislación de Colombia "excepcionalmente un solo acto hostil bastará para acreditar el acoso laboral”, en: Gamonal Contreras, Sergio; Prado López, Pamela, El mobbing... (n. 20), p. 70.

42 Siguiendo a ABajo Olivares, Francisco Javier, op. cit., p. 9.

43 Aunque la mayoría de las veces el estrés laboral sí será una consecuencia del mobbing.
} 
aislar o estigmatizar a un trabajador porque es diferente y esa diferencia resulta molesta, ya para la jerarquía de la empresa, ya para uno o más de sus colegas" 44 .

\section{DERECHOS VULNERADOS CON LA FIGURA DEL MOBBING}

Dado que el mobbing no se encuentra reconocido en forma explícita en el ordenamiento jurídico ${ }^{45}$, cobra gran relevancia determinar qué derechos fundamentales se ven afectados con esta figura, pues las herramientas de protección de estos derechos serán los que permitirán la real tutela contra el acoso psíquico, "esta ausencia de tipificación legal no impide advertir que el acoso psíquico laboral configura un atentado grave contra la dignidad de la persona y contra los derechos que le son inherentes; vale decir, contra los valores o principios-base de nuestra Constitución y, por cierto, los de cualquier nación civilizada". De ahí que sea válido extrapolar el juicio de la jurisprudencia española, según el cual el acoso psíquico en el trabajo constituye "un auténtico paradigma de comportamiento radicalmente prohibido por el Estado de Derecho" 46.

\subsection{MOBBING COMO ILfCITO PLURIOFENSIVO DE DERECHOS FUNDAMENTALES}

$\mathrm{El}$ acoso psíquico puede revestir diversas formas que pueden acarrear afectación de derechos fundamentales que se encuentran amparados en la Constitución de la República así como en tratados internacionales ratificados por Chile. Es por ello que se ha conceptualizado el mobbing como un ilícito constitucional pluriofensivo, que puede vulnerar derechos, como el derecho a la integridad física y psíquica (artículo $19 \mathrm{~N}^{\circ} 1$ de la Constitución Política en relación al artículo 184 del Código del Trabajo), el derecho a la intimidad (artículo $19 \mathrm{~N}^{\circ} 4$ ), el derecho a la no discriminación laboral (19 $\mathrm{N}^{\circ} 6$ en vinculación con el artículo $2^{\circ}$ y 62 bis del Código del Trabajo), todos los cuales se derivan del derecho a la dignidad personal ${ }^{47}$ (artículo $1^{\circ}$ de la Constitución Política en relación a los artículos $2^{\circ}$ y $5^{\circ}$ del Código del Trabajo).

\subsection{CONSTITUCIONALIZACIÓN DEL DERECHO LABORAL Y EFICACIA HORIZONTAL DE LOS DERECHOS FUNDAMENTALES}

La proliferación en la identificación de normas constitucionales en otras ramas del derecho, como en el derecho laboral, ha sido un fenómeno reciente en Chile, que conlleva

\footnotetext{
44 Palavecino Cáceres, Claudio, op. cit.

${ }^{45} \mathrm{La}$ situación chilena dista de la legislación francesa que "sanciona como delito el acoso moral con penas de prisión y multa", en: Gamonal Contreras, Sergio; Prado López, Pamela, El mobbing... (n. 20), p. 56. Sin embargo, en Chile existe el proyecto de ley Boletín 3198-13 para modificar "el Código del Trabajo sancionando las prácticas de sicoterror laboral", el cual ingresó a la Cámara de Diputados el 4 de marzo de 2003 y que actualmente se encuentra en su segundo trámite constitucional en el Senado. Información disponible en <http:///sil.congreso.cl/>

46 Palavecino Cáceres, Claudio, op. cit.

47 José Luis Cea define la dignidad como "la cualidad del ser humano predicable única o exclusivamente como atributo suyo, coherente con su inteligencia, libertad e igualdad, en fin, con su capacidad de decidir y de asumir la consiguiente responsabilidad, atributos de racionalidad que lo erigen en un depósito máximo o supremo de valores que integran su espíritu o entidad corporal Es sobre tal base que, después, son proclamados los derechos y deberes innatos del hombre, pues resultan ser inherentes a ella", en: él mismo, Tratado de la Constitución de 1980, Santiago, 1988, citado en: CAAMANo Rojo, Eduardo; Carvajal Godoy, Gabriela; Jiménez Trejo, Patricio, El Acoso Sexual en la empresa. Análisis de la Ley 20.005, Santiago, 2005.
} 
importantes implicancias, "un ordenamiento jurídico constitucionalizado se caracteriza por una Constitución extremadamente invasora, entremetida, capaz de condicionar tanto la legislación como la jurisprudencia y el estilo doctrinal, la acción de los actores políticos, así como las relaciones sociales" 48 .

La Constitución Política de 1980 reconoce derechos específicamente laborales, como la libertad de trabajo, la justa retribución y la no discriminación laboral, pero también reconoce otros derechos que se vinculan a la calidad de la persona de trabajador, como la integridad física y psíquica, el respeto y protección a la vida privada, honra, inviolabilidad de toda forma de comunicación privada, entre otros. Estos derechos reconocidos y garantizados en la legislación laboral, conllevan a la utilización -recientemente proliferada- de "derechos laborales inespecíficos" ${ }^{49}$ o de "ciudadanía en la empresa" 50 :

"cuando nos referimos a la ciudadanía en la empresa no hablamos de estos derechos fundamentales laborales propiamente tales, sino de aquellos derechos que tiene el trabajador como ciudadano, derechos civiles y políticos que, en cierta forma, quedaban disminuidos en la relación de trabajo, ya sea por la necesidad de una mejora urgente de las condiciones económicas y de trabajo o por efecto de la exarcebación de la potestad de mando del empleador (reconocida expresamente en la legislación por medio del binomio 'poder de dirección/subordinación')" 51 .

Directamente vinculado a la constitucionalización del derecho laboral, encontramos la aplicabilidad directa de las normas constitucionales en las relaciones entre particulares, a lo cual se le ha denominado "eficacia horizontal de los derechos fundamentales". En el siglo XIX los derechos fundamentales se proyectaban con eficacia vertical, es decir, se defendía al individuo ante el poder público pero no se le reconocía tal defensa entre los particulares. Hoy en día, la Constitución Política chilena reconoce en forma expresa tal horizontalidad en su artículo $6^{\circ}$ inciso segundo que dispone la aplicación directa de la Constitución al Estado y a todas las personas, y mejor aún, ha comenzado a utilizarse en forma concreta ${ }^{52}$ en aras de fomentar el respeto de los derechos fundamentales:

"En Chile desde hace algún tiempo se ha sostenido la plena vigencia de los derechos fundamentales o garantías constitucionales en el ámbito de las relaciones laborales, no en razón de su incorporación por parte de la ley, sino simplemente por el llamado 'efecto horizontal' de los derechos constitucionales, principio reconocido

\footnotetext{
48 GUASTINI, R. "La constitucionalización del ordenamiento jurídico: el caso italiano", en: AA. VV. Neoconstitucionalismo, Trotta, Madrid, 2003, p. 49, citado en: UGarTe CaTAlDo, José Luis, Tutela de... (n. 1), p. 8.

${ }^{49} \mathrm{Al}$ respecto, véase el Capítulo I punto 1 de Gamonal ConTreras, Sergio, El Procedimiento de tutela de los derechos laborales, primera edición, Editorial LexisNexis, Santiago, 2007, y PALOMEQUe LÓPEZ, Manuel Carlos, Los Derechos laborales en la Constitución española, Centro de Estudios Constitucionales, Madrid, 1991.

${ }^{50} \mathrm{Al}$ respecto, véase el Capítulo 8 de Gamonal ConTreras, Sergio; Guidi Moggia, Caterina, Manual... (n. 21).

51 Gamonal Contreras, Sergio, El procedimiento... (n. 49), p. 7.

52 Ugarte precisa que "pese al reconocimiento normativo de la eficacia horizontal de los derechos fundamentales del trabajador en nuestro orden jurídico, ello no había significado hasta ahora la vigencia efectiva de los mismos, cuestión que la doctrina había destacado anotando profundo divorcio entre las normas y la realidad. Era lo que denominábamos nuestro particular macondo jurídico", en: UGARTE CATALDO, José Luis, Tutela de... (n. 1), p. 17.
} 
en nuestra ley fundamental, en los artículos $6^{\circ}$ y $7^{\circ}$, mediante el nombre de "principio de vinculación directa de la Constitución" que lo hace plenamente aplicable en toda relación entre particulares" 53 .

\subsection{FUENTES CHILENAS DE RECONOCIMIENTO DE DERECHOS FUNDAMENTALES}

Si nuestro objetivo como sociedad es propender a un ambiente laboral digno y de respeto, fomentar el respeto de los derechos fundamentales al interior de la empresa debiera ser tarea de todos. Medidas de prevención, normas sancionatorias y resarcitorias de los actos ofensivos, el incentivo a la deferencia entre pares y rangos jerárquicos distintos debiera ser la tónica en el contenido de las normas que reconocen los derechos fundamentales.

López manifiesta que:

"Todos estos derechos operan como una limitación de los poderes empresariales respecto a la ejecución del trabajo humano; garantizan una contrapartida humana al acuerdo de trabajo por dinero: al considerar al trabajador un sujeto de derechos, necesariamente debe asegurarse que los derechos fundamentales de la persona humana no se pierdan o disminuyan por el hecho de ponerse bajo las órdenes de quien compra un trabajo para utilizarlo en su propio provecho. El acuerdo económico de remuneración a cambio de trabajo no hace menos persona o ciudadano al trabajador. Hay pues, valores no patrimoniales en el intercambio económico del trabajo; el trabajador es titular de derechos y su trabajo no puede utilizarse sino respetando la dignidad humana del prestador. Los derechos fundamentales de la persona humana no pierden vigencia en una relación de trabajo; antes bien, garantizan que los trabajadores no se vean reducidos solo a una función productiva y económica" 54 .

En los últimos años se ha ampliado el reconocimiento y promoción de derechos fundamentales en las fuentes normativas chilenas:

a) Los tratados internacionales: aquellos que reconocen derechos humanos ratificados por Chile han incorporado a nuestra legislación normas de protección de los derechos fundamentales ${ }^{55}$, por aplicación del artículo $5^{\circ}$ inciso $2^{56}$ de la Constitución.

b) La Constitución Política: es la gran fuente normativa de reconocimiento expreso de derechos laborales específicos como inespecíficos, así como establece un principio de vinculación directa de la Constitución.

\footnotetext{
${ }^{53}$ Lizama Portal, Luis y Ugarte Cataldo, José Luis, Nueva Ley... (n. 1), p. 4.

${ }^{54}$ LOPEZ, Diego, "Los derechos fundamentales en el trabajo: garantía de libertad y dignidad de las personas que trabajan", Santiago, 2004, disponible en: < http://works.bepress.com/cgi/viewcontent.cgi?article $=1021$ \&context=eduardo_andres_ caamano_rojo>

${ }^{55} \mathrm{Al}$ respecto han sido ratificados por Chile el Pacto Internacional de Derechos económicos, sociales y culturales de 1966, el Pacto internacional de derechos civiles y políticos de 1966, la Convención Americana sobre derechos humanos de 1969 (conocida como Pacto de San José de Costa Rica), entre otros.

${ }^{56} \mathrm{El}$ referido artículo expresa que "El ejercicio de la soberanía reconoce como limitación el respeto de los derechos esenciales que emanan de la naturaleza humana. Es deber de los órganos del Estado respetar y promover tales derechos, garantizados por la Constitución, así como los tratados internacionales ratificados por Chile y que se encuentren vigentes".
} 
c) El Código del Trabajo y las leyes laborales: a partir del año 2000 se comenzaron a incorporar expresamente los derechos fundamentales como límite al ejercicio de las facultades del juez. Así, la Ley $\mathrm{N}^{\circ} 19.759$ incorporó un nuevo inciso primero al artículo $5^{\circ}$ del Código del Trabajo en el cual los reconoce como límite a las potestades del empleador. En el actual texto del artículo $5^{\circ}$ del Código del Trabajo es posible "constatar que la protección al trabajador derivada del respeto debido a sus derechos fundamentales (inciso l) se superpone y complementa a la protección tradicional que se le reconoce en cuanto trabajador, mediante la declaración de irrenunciabilidad de los derechos mínimos que le otorga la legislación laboral (inciso 2)" 57 .

Asimismo, se introducen modificaciones al artículo $2^{\circ 58}, 154-\mathrm{A}^{59}, 154,154$ bis, 194, 62 bis $^{60}$, entre otras, que siguen este lineamiento.

Con la reforma laboral introducida por las leyes $\mathrm{N}^{\circ} 20.087,20.022,20.023,20.252$ y 20.260 , se contemplan modificaciones a la tramitación de los procedimientos laborales, y se introduce un procedimiento de aplicación general con características especiales, denominado procedimiento de tutela. Es a través de este procedimiento que se conocen las cuestiones suscitadas en la relación laboral que afecten los derechos fundamentales ${ }^{61}$ de los trabajadores, estando vigente la relación laboral como con ocasión del despido.

d) Jurisprudencia administrativa: existen dos órganos de aplicación del derecho laboral que tienen relevancia en la interpretación de la legislación del trabajo: la Dirección del Trabajo y los tribunales de justicia laborales. En efecto, "la aplicación del derecho supone para el órgano judicial y administrativo la individualización o concretización de la norma general mediante la producción de una norma individual" 62 .

La función de reconocimiento de los derechos fundamentales al interior de la empresa ha sido reconocida por la jurisprudencia de la Dirección del Trabajo a través del pronunciamiento de diversos dictámenes que los reconocen expresamente. Ya el dictamen $\mathrm{N}^{\circ} 287 / 014$, de 11 de enero de 1996, estableció que:

“...mientras el sistema jurídico dota al empleador de lo que la doctrina llama el poder de dirección y de disciplina, esto es, de la facultad para dirigir y mantener el orden dentro de la empresa, que de alguna manera es manifestación de los derechos constitucionales de propiedad y de la libertad para desarrollar cualquier actividad económica, dicha facultad se encuentra jurídicamente limitada por las garantías constitucionales dirigidas a proteger la dignidad y honra de las personas".

\footnotetext{
57 CaAmaño Rojo, Eduardo, "La ley de subcontratación y la tutela de los derechos fundamentales de los trabajadores de servicios transitorios", en: Ius et Praxis [online]. 2007, vol. 13, N² 2, Talca, pp. 157-194 [citado 2010-02-22]. Disponible en: <http://www.scielo.cl/scielo.php?script=sci_arttext\&pid=S0718-00122007000200008\&lng=es\&nrm=iso> ISSN 07180012. doi: 10.4067/S0718-00122007000200008 [consulta 22 de febrero de 2010].

${ }^{58}$ En relación con la no discriminación y al no respeto de la dignidad del trabajador.

59 Modificación relativa a los contratos de trabajadores de artes y espectáculos, en que se señala que dichos contratos no podrán afactar la libertad de creación del artista. Y el artículo 154 inciso final establece que las obligaciones y prohibiciones del reglamento interno deben respetar la dignidad del trabajador.

${ }^{60}$ Con expreso reconocimiento al principio de igualdad de remuneraciones.

${ }^{61}$ Aquellos expresamente señalados en el artículo 485 del Código del Trabajo.

${ }^{62}$ LizAMa PORTAL, Luis y UGarTe CATALDO, José Luis, Interpretación y Derechos Fundamentales en la Empresa, Editorial ConoSur Ltda., Santiago, 1998, p. 56.
} 
Y se ha reconocido estas garantías a propósito de la utilización de ciertos medios de control por parte de los empleadores, por ejemplo, del uso del polígrafo, alcoholemia, cámaras de seguridad al interior de la empresa. En el dictamen No 684/50, de 6 de febrero de 1997, se expresó que si un empleador, con el objeto de prevenir delitos, tales como el contrabando y tráfico de drogas y estupefacientes, desea requerir de sus postulantes a cargos de seguridad y a quienes actualmente se desempeñen en dichos cargos, el someterse a un examen de polígrafo, deberá determinarse primeramente si el ejercicio de tal derecho vulnera el ejercicio de otros derechos fundamentales. El dictamen manifiesta que se pone en juego el derecho a la integridad psíquica de la persona, puesto que al ser examinado mediante un polígrafo, objetivamente se estaría colocando a la persona en una situación "estresante", fuera de lo normal o, en el mejor de los casos, en una situación que potencialmente puede convertirse en desintegradora de la "psique" de la persona. Por otro lado el dictamen No 2852/158, de 30 de agosto de 2002, señaló que:

"De conformidad a la doctrina vigente de este Servicio, contenida en el dictamen $2328 / 130$, de 19.07.2002, el reconocimiento del carácter de límites infranqueables que los derechos fundamentales, en particular del derecho a la intimidad, vida privada u honra de los trabajadores, poseen respecto de los poderes empresariales (inciso primero del artículo $5^{\circ}$ del Código del Trabajo), así como la prevalencia que la dignidad de los trabajadores tiene respecto de los mecanismos de control empresarial (inciso final, del artículo 154 del Código del Trabajo), lleva necesariamente a concluir que la utilización de mecanismos de control audiovisual (grabaciones por videocámaras) en los vehículos de la locomoción colectiva urbana, solo resulta lícita cuando ellos objetivamente se justifican por requerimientos o exigencias técnicas de los procesos productivos o por razones de seguridad de los conductores o de los pasajeros, debiendo ser el control de la actividad del trabajador solo un resultado secundario o accidental del mismo"63.

El dictamen $\mathrm{N}^{\circ} 2856 / 162$, de 30 de agosto de 2002, concluye señalando que:

"a la luz de las normas constitucionales, tratados internacionales vinculantes para el Estado chileno, disposiciones legales citadas, en particular en lo referido al inciso primero, del artículo $5^{\circ}$, del Código del Trabajo, y a las consideraciones y argumentaciones esbozadas, es posible concluir que los derechos fundamentales respecto de los cuales es titular la persona del trabajador en cuanto a su condición de ciudadano, han de servir como medida de valoración de los poderes empresariales, erigiéndose en límites infranqueables al ejercicio por parte del empresario de dichos poderes".

De esta forma la Dirección del Trabajo ha sido clara en señalar que "toda medida de control, solo puede efectuarse por medios idóneos y concordantes con la naturaleza de la

\footnotetext{
${ }^{63}$ En esa misma línea el dictamen ORD No 4822/207 de 11 de noviembre de 2003.
} 
relación laboral y, en todo caso, su aplicación debe ser general, garantizándose la impersonalidad de la medida, para respetar la dignidad del trabajador"64.

Con posterioridad a la reforma laboral, la Dirección del Trabajo emitió un completo pronunciamiento sobre el carácter de límites infranqueables respecto de las potestades del empleador que tienen los derechos fundamentales de los trabajadores, a través del dictamen No 2210/035 de fecha 10 de junio de 2009. Dicho dictamen expresa que:

"existen ciertos requisitos que se deben seguir al imponer límites a un derecho fundamental y que se pueden englobar en la aplicación del denominado 'principio de proporcionalidad', resultando, a partir de este, que el empleador, para, en un caso concreto, poder limitar el ejercicio de los derechos fundamentales del trabajador o trabajadora, tendrá que cumplir con el 'principio de la adecuación', que supone que el medio empleado debe ser apto o idóneo para la consecución del fin propuesto, resultando inadecuada en consecuencia, la limitación de un derecho fundamental cuando ella no sirva para proteger la garantía constitucional en conflicto; con el 'principio de necesidad', según el cual la medida limitativa sea la única capaz de obtener el fin perseguido, de manera tal que no exista otra forma de alcanzar dicho objetivo sin restringir el derecho o que fuese menos gravosa, y con el 'principio de proporcionalidad en sentido estricto', a partir del cual se determina si la limitación del derecho fundamental resulta razonable en relación con la importancia del derecho que se trata de proteger con la restricción".

\section{e) Jurisprudencia judicial}

Resulta determinante para la vigencia de los derechos fundamentales en una empresa, que exista ponderación de los mismos, particularmente por la relación de poder que caracteriza a la relación laboral. Es por ello, se ha entendido que el poder empresarial:

"ha de suponer en cuanto a su ejercicio el respeto a las garantías fundamentales que la propia Constitución reconoce a todo ciudadano y por ende al trabajador. En efecto, como se ha apuntado, los poderes empresariales no puede suponer a priori una relativización o matización del derecho fundamental, más bien, este es el que actúa como un freno insalvable al ejercicio de tales poderes. Por lo tanto, el problema no tiene solo una connotación contractual -modalización de la vida dentro de la empresa según las directrices o la organización empresarial-, tiene también un componente que escapa al limitado y circunscrito ámbito del contrato de trabajo para trasladarse a la órbita constitucional, esto es, al ejercicio por parte del trabajador de derechos que trascienden su categorización como trabajador para amoldarse a un plano omnicomprensivo de su personalidad toda. En consecuencia, dicho poder -expresión de las necesidades organizativas o productivas del empresario, pero delimitado jurídicamente en virtud del contrato de trabajo y de la ley- necesariamente

64 En el mismo sentido, véase WALKer ERRázUriz, Francisco, Derecho de las relaciones laborales, primera edición, Editorial Universitaria, Santiago, 2003, p. 359. 
ha de verse afectado en alguna medida en aras del respeto pleno de los derechos fundamentales del trabajador" 65 .

Los derechos fundamentales no son absolutos, en el sentido de que tienen límites externos (con otros derechos) así como límites internos (núcleo esencial ${ }^{66}$ ), "La vigencia de los derechos ciudadanos dentro de la empresa implica una labor de ponderación por parte del aplicador del derecho, donde las potestades del empleador en cierta forma deben ser reformuladas o limitadas al tenor de dichos derechos del trabajador, conformando lo que Baylos denomina las 'dos ciudadanías' del trabajador, fuera y dentro de la empresa" 67 .

Siguiendo a Fernando Valés Dal-Re, Melis señala que "Se trata pues, de un problema de limitación -límites- y no de delimitación (argumentos extraconstitucionales: contractuales u organizativos, que actúan como elementos delimitadores del contenido del derecho fundamental y por lo mismo expulsando de su esfera protectora aquellas manifestaciones que colisionan con aquellos" 68 .

Por tanto, la relación entre titulares de derechos fundamentales conlleva necesariamente a la labor de ponderación del juez.

En lo relativo a la regulación legal de los derechos fundamentales, nuestra doctrina constitucional, y gran parte de la comparada, postula como criterio a seguir el principio de proporcionalidad comprensivo de tres subprincipios: el de adecuación, relativo al control, de idoneidad de la norma; el de necesidad que determina la prescindibilidad o no de la intervención, estableciendo el peligro y considerando la necesidad de producir el menor daño; y el principio de proporcionalidad en sentido estricto, que determina la racionalidad de la intervención según su objeto y los efectos que produce ${ }^{69,70}$.

Si bien los tribunales de justicia chilenos habían comenzado a reconocer los límites a las facultades del empleador respecto a la vulneración de los derechos fundamentales del trabajador $^{71}$, podemos afirmar que es con la aparición del procedimiento de tutela cuando

\footnotetext{
${ }^{65}$ Dictamen ORD No 2328/130 de 19 de julio de 2002, disponible en <www.dt.gob.cl>

${ }^{66}$ En ese sentido, un extracto de la sentencia en procedimiento de tutela T-1-2008 del Juzgado de Letras del Trabajo de Copiapó (caratulado Madrid con Sociedad de Profesionales Kronos Ltda.): "Los derechos fundamentales, sean específicos, inespecíficos, laboralizados o no, no son absolutos y por lo mismo reconocen como límite el ejercicio de otros bienes o garantías constitucionales; en razón de ello, en su ejercicio y siempre teniendo presente que nunca se puede afectar el núcleo irreductible de un derecho fundamental -lo conocido en doctrina como el límite a los límites-, en el ejercicio de uno de estos derechos puede producirse un conflicto con otros derechos o bienes constitucionalmente protegidos".

67 Gamonal Contreras, Sergio, El procedimiento... (n. 49), p. 6.

68 Melis, Christian, "Derechos fundamentales y empresas: apuntes para una configuración dogmático-jurídica", en: Anuario de Derecho del Trabajo y Seguridad Social No 3/2004, Derechos Fundamentales. Homenaje al Profesor Patricio Novoa Fuenzalida, Sociedad Chilena de Derecho del Trabajo y de la Seguridad Social, Santiago, p. 114.

${ }^{69}$ Gamonal Contreras, Sergio, El procedimiento... (n. 49), p. 10.

${ }^{70}$ En el mismo sentido, Nogueira AlCalA, Humberto, Dogmática Constitucional, Editorial Universitaria de Talca, Talca, 1997, p. 184.

${ }^{71}$ Por ejemplo las sentencias causa rol $\mathrm{N}^{\circ}$ 156-2005 Corte de Apelaciones de Puerto Montt, de fecha 30 de septiembre de 2005, la causa rol N 665-2006 de la Corte de Apelaciones de Valdivia, de fecha 6 de septiembre de 2006, y la causa rol $\mathrm{N}^{\circ}$ 4858-2006, en recurso de protección interpuesto por una funcionaría de la Municipalidad de Valdivia basado en conductas de acoso laboral, todas citadas por CAAMAÑo Rojo, Eduardo, "La ley de subcontratación y la tutela de los derechos fundamentales de los trabajadores de servicios transitorios", en: Ius et Praxis [online]. 2007, vol. 13, $\mathrm{N}^{\circ} 2$, Talca, pp. 157-194 [citado 2010-02-22]. Disponible en: <http://www.scielo.cl/scielo.php?script=sci_arttext\&pid=S0718$00122007000200008 \& \operatorname{lng}=e s \& n r m=i s o>$. ISSN 0718-0012. doi: 10.4067/S0718-00122007000200008 [consulta de fecha 22 de febrero de 2010].
} 
se logra la mayor apertura en el reconocimiento de estos límites, abriendo la gran compuerta a la ponderación de los derechos fundamentales como límites entre sí. Ejemplos de esta ponderación lo constituyen las sentencias pronunciadas en los procedimientos de tutela conocidos como "caso kronos"72 de Copiapó y "colegio alemán"73 de Valparaíso.

En el "caso kronos" el empleador había leído el respaldo computacional de una conversación privada de la trabajadora de la empresa, que luego habría utilizado en forma pública para despedirla, afectando de esta forma su derecho a la inviolabilidad de toda forma de comunicación privada. El considerando octavo de la sentencia que acoge la tutela con ocasión del despido, el juez laboral de Copiapó señala que:

"en la mayoría de los ordenamientos jurídicos, incluido el nuestro, se ha impuesto el método de la ponderación guiado por el principio de proporcionalidad en sentido amplio, creado por la jurisprudencia alemana, principalmente a partir de los escritos de Robert Alexy, el cual consiste básicamente en pesar los derechos y bienes en juego, persiguiendo que cada derecho se sacrifique por el otro en la menor medida posible y solo en la medida que ese sacrificio sea racional y no afecte el ya mencionado núcleo esencial de los derechos fundamentales".

Esta ponderación a través del principio de proporcionalidad en sentido amplio, opera a través de tres subjuicios: el de la adecuación, el de la necesidad y el de la proporcionalidad en sentido estricto. Si hecho el examen aludido, la conducta del empleador supera esos tres estándares establecidos, se podrá decir que prima el derecho del empleador y que no ha existido afectación sancionable de los derechos fundamentales del trabajador; por el contrario, si no resiste alguno de esos análisis, la conclusión inevitable es que el actuar del empleador es prohibido por nuestro ordenamiento jurídico por ser vulneratorio inaceptablemente de los derechos fundamentales que asisten al trabajador.

En el procedimiento de tutela contra el "colegio alemán", este colegio despide a una trabajadora por la causal del artículo 161 inciso primero del Código del Trabajo, necesidades de la empresa, pero la trabajadora esgrime que dicho despido ha considerado únicamente su edad y el hecho de que su sueldo era de los más altos que se pagaba, por lo que correspondería a un despido discriminatorio de carácter grave. En el considerando decimocuarto de la parte resolutiva de la sentencia recaída en dicha causa, la jueza Ximena Cárcamo, establece que:

"nuestro procedimiento de tutela, ha venido a crear un cauce procesal para la protección de derechos no patrimoniales, vinculados, más que al intercambio de servicios por dinero, a la dimensión moral del sujeto entendido como ciudadano. Frente al reconocimiento de lo complejo y agotadoras que pueden ser las relaciones entre particulares en el ámbito de la empresa, luego de destruida la comunidad de intereses, siendo lo único que dejaría verdaderamente indemne un despido vulneratorio, el

\footnotetext{
72 Que corresponde a la causa RIT T- N¹-2008, tramitada ante el Juzgado de Letras del Trabajo de Copiapó.

${ }^{73}$ Que corresponde a la causa RIT T- N²-2009, tramitada ante el Juzgado de Letras del Trabajo de Valparaíso.
} 
legislador ha señalado la opción del establecimiento de una indemnización sancionatoria, que va de seis a once meses de la última remuneración mensual. Establecida la extensión del tramo por el legislador, corresponde al juez fijar en concreto el quantum de la sanción, ejercicio en el que, en el caso particular, tendrá en consideración, que la trabajadora perdió su empleo, a raíz de esta vulneración, a solo dos años de encontrarse, de acuerdo con la ley, en condiciones de decidir si jubilaría, elección que, dada la decisión de tercero que la afectó, deberá realizar en condiciones bastante más desventajosas que las que hubiera tenido de haberla podido ejercer si hubiera podido hacerlo formando parte de la institución a la que por 18 años perteneció y que en tales condiciones, la edad de la actora, incluso dificulta la obtención de un nuevo empleo, lo que transforma la vulneración efectuada por el empleador en grave".

\section{PROTECCIÓN JURÍDICA FRENTE AL MOBBING}

Ya que la figura del acoso psíquico laboral no se encuentra regulada en forma expresa en nuestro ordenamiento jurídico, los cauces jurídicos que protegen los derechos fundamentales que se ven vulnerados con el mobbing -y que se identificarán caso a caso-, serán los medios con los cuales la víctima del mobbing podrá enfrentar la figura.

Antes de enumerar los cauces jurídicos que existen en nuestro ordenamiento, conviene preguntarse cuál es el procedimiento idóneo que sería eficaz para sancionar el acoso a la víctima. Si se le están lesionando derechos fundamentales a la víctima, es lógico pensar que se quiere inhibir la conducta en un sentido ejemplificador, que se quiere detener inmediatamente el hostigamiento en caso de que todavía se presente y que se quiere resarcir a la víctima de modo tal que se encuentre en la misma situación a la que se encontraba antes de la afectación de sus derechos.

Hasta antes de la instauración de la reforma laboral ${ }^{74}$ los cauces jurídicos para dirigirse contra el mobbing consistían principalmente en la acción de protección; en acciones indemnizatorias de perjuicios interpuestas en sede ordinaria, y en el despido indirecto.

La nueva reforma introdujo un nuevo procedimiento en sede laboral por afectación de derechos fundamentales, denominado procedimiento de tutela laboral ${ }^{75}$, que si bien enumera en forma taxativa los derechos fundamentales y garantías a los cuales protege ${ }^{76}$, presenta diversas características que permiten afirmar que recoge la doctrina de la horizontalidad de los derechos fundamentales ${ }^{77}$.

\footnotetext{
${ }^{74}$ La reforma laboral que entró a regir con aplicación gradual, "El sistema de vigencia diferida de la Reforma Laboral por regiones, al estilo de la reforma procesal penal, se extiende en un plazo que va desde el 31 de marzo de 2008 al 30 de octubre de 2009 (Artículo 16 de la Ley No 20.022). En efecto, en las regiones III y XII, la ley comenzó a regir el 31 de marzo de 2008; en la I, IV, V y XIV, rige desde el 31 de octubre de 2008; en la II, VI, VII y VIII, rige desde el 30 de abril de 2009; en la Región Metropolitana, rige desde el 31 de agosto de 2009, y finalmente en las regiones IX, X, XI y XV, la reforma laboral comenzó a regir el 30 de octubre de 2009.

75 Regulado en el párrafo sexto del Capítulo V del Código del Trabajo, en los artículos 485 a 495 .

${ }^{76}$ Bajo esta 6ptica el procedimiento de tutela laboral es más restrictivo en su consideración de derechos y garantías que la redacción actual del artículo $5^{\circ}$ inciso primero del Código del Trabajo.

${ }_{77}$ Asimismo este procedimiento se sitúa en medio de los principios de celeridad, inmediación, gratuidad, buena fe e impulso procesal de oficio que caracterizan la nueva reforma laboral, con mecanismos procesales de oralidad, publicidad y concentración.
} 


\subsection{CAUCES JURÍDICOS PARA ENFRENTAR EL MOBBING}

a) Despido indirecto: frente a determinadas conductas del empleador, el trabajador puede poner término unilateralmente a su contrato de trabajo a través de la figura del despido indirecto o autodespido establecido en el artículo 171 del Código del Trabajo ${ }^{78}$. De poder acreditar la causal de término de contrato que invoca, obtendrá las indemnizaciones con que la ley sanciona el despido injustificado, de lo contrario, el juez estimará que ha operado una renuncia.

Estudiando las diversas causales de término de la relación laboral que permitirían autodespedirse por mobbing, aparecen las conductas graves y debidamente comprobadas ${ }^{79}$ establecidas en el artículo $160 \mathrm{~N}^{\circ} 1$ letra a) falta de probidad; la del $160 \mathrm{~N}^{\circ} 1$ letra c) injurias, que comprende las expresiones verbales de obra o de palabra que agravian a otro $^{80}$; la del $160 \mathrm{~N}^{\circ} 5$, actos, omisiones o imprudencias temerarias que afecten a la seguridad o actividad de los trabajadores o a la salud de estos, y la del $160 \mathrm{~N}^{\circ} 7$, incumplimiento grave de las obligaciones que impone el contrato ${ }^{81}$. Si se está frente a un mobbing horizontal, se podrá invocar un autodespido basado en la causal del artículo $160 \mathrm{~N}^{\circ} 7$, por el incumplimiento del deber de protección de la vida y salud de sus trabajadores ordenado en el artículo 184 del Código del Trabajo "puede concluirse que la conducta desplegada por el acosado afecta la salud de un trabajador, por lo que el empleador que la tolera, aun cuando no la aliente, será responsable de un incumplimiento contractual" 82 . Pero si se está frente a un mobbing vertical descendente resulta preferente invocar la causal del artículo $160 \mathrm{~N}^{\circ} 1$ letra a). Al respecto, Gamonal ha señalado que "claramente estamos frente a una falta de probidad del empleador (...) La falta de probidad implica honradez, en cuanto rectitud de ánimo e integridad en el obrar" ${ }^{3}$. En este caso se podrá acumular a las indemnizaciones laborales otra adicional por el daño moral provocado en el trabajador, ya que el artículo 171 en su inciso segundo preceptúa que "Tratándose de la aplicación de las causales de las letras a) y b) del número 1 del artículo 160, el trabajador afectado podrá reclamar del empleador, simultáneamente con el ejercicio de la acción que concede en el inciso anterior, las otras indemnizaciones a que tenga derecho".

\footnotetext{
${ }^{78} \mathrm{El}$ artículo 171 del Código del Trabajo establece como causales para invocar el despido indirecto el 1, 5 ó 7 del artículo 160 del Código del Trabajo.

79 Para Palavecino, "Lo que torna destructivas, y por ende graves, actuaciones semejantes es lo que precisamente las transforma en acoso, esto es, su repetición en el tiempo. La reiteración de estas prácticas y su efecto de conjunto sobre la salud psíquica de la víctima será, entonces, lo que permitirá al juez calificarlas como conductas indebidas de carácter grave", en: PAlaVecino CÁCERES, Claudio, op. cit.

<http://www.scielo.cl/scielo.php?script=sci_arttext\&pid=S0718-09502004000200003\&lng=es\&nrm=iso> ISSN 07180950. doi: 10.4067/S0718-09502004000200003 [consulta 22 de febrero de 2010].

80 Por ejemplo, el Tribunal Superior de Justicia de la Provincia de Río Negro, el 6 de abril de 2005, en causa Expte. No 17.505/02-STJ caratulado Dufey, Rosario Beatriz C/ Entretenimiento Patagonia S.A. s/Sumario S/ Inaplicabilidad de Ley, hizo lugar al planteamiento de una trabajadora que alegó "maltrato psicológico" como causal de autodespido, pese a que en esa fecha no existía legislación expresa al respecto. Texto completo del fallo disponible en la página web del Colegio de Abogados del Departamento Judicial de Quilmes, Argentina: <http://www.caq.org.ar/shop/detallenot.asp? notid=700>

81 Sin perjuicio de que en caso de un mobbing sexual también se podrá invocar la causal del artículo $160 \mathrm{~N}^{\circ} 1$ letra b).

82 Lanata Fuenzalida, Gabriela, Contrato... (n. 38), p. 76.

83 Gamonal Contreras, Sergio; Prado López, Pamela, El mobbing... (n. 20), p. 87.
} 
La nueva normativa que introduce el procedimiento de tutela no hace referencia en forma expresa a la posibilidad de accionar de despido indirecto y de tutela de derechos fundamentales. Sin embargo, quien desee autodespedirse por motivo de un acoso psíquico podrá, según la redacción del artículo 489 del Código del Trabajo, accionar por tutela de derechos fundamentales y en subsidio de despido indirecto. Ello por cuanto dicho artículo expresa "si de los mismos hechos emanaren dos o más acciones de naturaleza laboral, y una de ellas fuese la de tutela laboral de que se trata este Párrafo, dichas acciones deberán ser ejercidas conjuntamente en un mismo juicio, salvo si se tratare de la acción por despido injustificado, indebido o improcedente, la que deberá interponerse subsidiariamente", y si bien no señala en forma expresa el término "despido indirecto", su sola denominación implica que la doctrina le atribuye los efectos de un despido propiamente tal, por ello se contemplan las indemnizaciones del artículo 168 del Código del Trabajo.

Si bien la utilización de este procedimiento implica la salida inmediata del trabajador de la fuente que está ocasionando el daño en su persona, procediendo el pago de las respectivas indemnizaciones por término de contrato de trabajo, cabe considerar que las indemnizaciones por perjuicios materiales y morales solo podrán solicitarse en caso de invocar la causal del artículo $160 \mathrm{~N}^{\circ} 1$ letra a) del Código del Trabajo ${ }^{84}$.

\section{b) Acción de protección}

La gran ventaja de la acción de protección que consagra la Constitución, es la facultad que tiene la Corte de Apelaciones de ordenar el cese de las prácticas constitutivas del acoso, sin embargo, "La construcción jurídicamente neutra del recurso de protección, y de la forma de tramitación en el autoacordado complementario, alejados de los principios propios del derecho del trabajo y de su rol compensador a favor del contratante más débil, produce una evidente insensibilidad de esta acción a la posición procesalmente débil del trabajador en litigios de derechos fundamentales y laborales y en general"85.

Con esta alternativa no es posible resarcir directamente los daños materiales y morales ocasionados a la víctima del $\operatorname{acoso}^{86}$, pero sí se podría posteriormente, accionar ordinariamente de indemnización de perjuicios.

Melis se ha referido a otras consecuencias de la aplicación de esta acción:

"En el plano laboral, el Recurso de Protección se ha transformado más que en un instrumento de amparo de los derechos fundamentales del trabajador, en un instru-

\footnotetext{
${ }^{84}$ Situación distinta se observa en la regulación del acoso sexual incorporada por la Ley $\mathrm{N}^{\circ} 20.005$, que establece expresamente la acumulación de indemnizaciones en sede laboral en el artículo 171 del Código del Trabajo (al referirse a la causal del artículo 160 letra b). Al respecto, Luis Lizama y José Luis Ugarte señalaron: "Con esta nueva regulación se salva una eventual discusión jurídica sobre la procedencia del cúmulo de indemnizaciones en estos casos y queda claro que las indemnizaciones por término de contrato de trabajo son de carácter tarifado -su monto depende de la última remuneración mensual devengada por el trabajador y de los años servidos en la empresa- y que por ello, no compensan todos los perjuicios que el trabajador -víctima de acoso sexual- puede sufrir con ocasión de dichas conductas", en: Lizama Portal, Luis y UGarte Cataldo, José Luis, Nueva Ley... (n. 1), p. 55.

85 Ugarte Cataldo, José Luis, El Nuevo... (n. 11), p. 130.

${ }^{86}$ Palavecino ha señalado que la "explicación de esta limitación se encuentra en el carácter puramente cautelar que la judicatura ha atribuido a la acción de protección, en virtud del cual "no puede transformarse esta acción en un procedimiento declarativo de lato conocimiento", como el que exige precisamente el reconocimiento de la tutela resarcitoria", en: PALAVECINO CÁCERES, Claudio, op. cit.
} 
mento idóneo para ello aunque no único- en un mecanismo que casi exclusivamente se ha limitado a coartar y cuestionar las atribuciones y facultades de la Dirección del Trabajo, con ello se ha perdido una gran oportunidad para que la jurisprudencia constitucional, tal y como lo hacen los Tribunales Constitucionales europeos o los Tribunales americanos, se constituyera en la punta de lanza en torno a la idea de vigencia de los derechos fundamentales en las relaciones laborales" 87.

El nuevo artículo 485 inciso final del Código del Trabajo ha tornado incompatible, en forma descendente, la acción de protección con el procedimiento de tutela ${ }^{88}$. Esto quiere decir que una vez interpuesta la acción de protección no procede interponer el procedimiento de tutela. Y por el contrario, la redacción si autoriza una compatibilidad ascendente, es decir, interpuesto el procedimiento de tutela sí se admitiría accionar de protección.

\section{c) Acciones Ordinarias}

Dependiendo del tipo de acoso moral, dependerá la naturaleza de la acción y el tribunal competente para conocer de la misma. Si la conducta acosadora proviene de los pares -mobbing horizontal-corresponderá impetrar una responsabilidad extracontractual a los acosadores, pero también se podrá perseguir una responsabilidad contractual del empleador que al permitir una situación de acoso laboral incumple con el deber de protección a la vida y salud de sus trabajadores que le ordena el artículo 184 del Código del Trabajo.

Asimismo, quien acciona por despido indirecto, también podrá perseguir las indemnizaciones por perjuicios materiales o morales en sede ordinaria.

Tratándose del caso del acoso sexual, la legislación laboral ha planteado la posibilidad expresa de accionar por "otras indemnizaciones" en sede laboral, sin embargo, la ausencia de regulación en el mobbing obligaría a demandar de perjuicios materiales y morales en sede ordinaria, a excepción del despido indirecto fundamentado en el artículo $160 \mathrm{~N}^{\circ} 1$ letra a) y del trabajador que ataca la figura del mobbing a través del procedimiento de tutela, donde se contempla a juicio de ciertos autores una indemnización especial de seis a once meses de remuneración que incluiría el daño moral ${ }^{89}$. En los demás casos, la sede sería la ordinaria para perseguir el daño moral.

d) Otros. Limites al ius variandi y ley de igualdad de las remuneraciones

En ciertos casos el hostigamiento provocado por el mobbing puede revestir apariencias de legalidad, como por ejemplo, cuando el empleador utiliza la facultad del ius variandi que el legislador le reconoce en el artículo 12 del Código del Trabajo, para

\footnotetext{
${ }^{87}$ MELIS, Christian, op. cit., p. 110.

${ }^{88}$ El referido inciso señala: "Interpuesta la acción de protección a que se refiere el artículo 20 de la Constitución Política, en los casos que corresponda, no se podrá efectuar una denuncia de conformidad a las normas de este Párrafo, que se refiera a los mismos hechos".

${ }^{89}$ Gamonal plantea que por motivos de seguridad jurídica se establece un rango de seis a once meses de remuneración para la indemnización especial del procedimiento de tutela, en: GAMONAl CONTRERAS, Sergio; Prado LOPEZ, Pamela, El mobbing... (n. 20).
} 
modificar en forma unilateral la naturaleza de los servicios, lugar de trabajo y horario del subordinado. La exigencia de la ley es que lo anterior no implique un menoscabo para el trabajador:

"La ley utiliza la expresión menoscabo, sin especificar la naturaleza de este, de manera que la interdicción legal tiene un alcance lo suficientemente amplio como para excluir todo detrimento a la dignidad personal o profesional del trabajador. El inciso final del art. $12 \mathrm{CT}$, establece un procedimiento especial, a través del cual el trabajador afectado podrá reclamar, en el plazo de 30 días hábiles a contar del cambio de labores o de lugar de trabajo, ante el inspector del trabajo respectivo a fin de que este se pronuncie sobre el cumplimiento de las condiciones legales (...) Esta reclamación puede ser un instrumento preventivo eficaz ante las primeras actitudes de acoso jerárquico, cuando todavía es posible ponerle atajo con una actitud enérgica del trabajador"90.

Asimismo, la Ley $\mathrm{N}^{\circ} 20.348$ publicada en el Diario Oficial el 14 de junio de 2009 incorporó el artículo 62 bis al Código del Trabajo, el cual incorporó la obligación del empleador de dar cumplimiento al principio de igualdad de remuneraciones entre hombres y mujeres que presten un mismo trabajo. De forma tal que la persona que esté sufriendo amenazas o detrimento en su remuneración como manifestación de mobbing podrá realizar un procedimiento de reclamación que debe encontrarse regulado en el reglamento interno de la empresa ${ }^{91}$, y una vez concluido este procedimiento, podrá recurrir a la Inspección del Trabajo bajo la misma modalidad señalada para el ius variandi.

\subsection{APLICACIÓN DEL PROCEDIMIENTO DE TUTELA CONTRA EL MOBBING}

Una de las grandes novedades de la reforma al procedimiento laboral es la incorporación del párrafo 6 al Libro $V$ del Código del Trabajo que crea el procedimiento de tutela de laboral, concebido para conocer de "las cuestiones suscitadas en la relación laboral por aplicación de las normas laborales, que afecten los derechos fundamentales de los trabajadores (...) cuando aquellos derechos resulten lesionados en el ejercicio de las facultades del empleador" 92 .

Dentro de los derechos enumerados con en el procedimiento de tutela, que se pueden ver vulnerados con la figura del mobbing, podemos observar el derecho a la integridad física y psíquica de la persona (19 No 1 de la Constitución), el derecho a su

\footnotetext{
90 Palavecino Caceres, Claudio, op. cit.

${ }^{11}$ La misma ley introdujo el nuevo número 13 al artículo 154 que establece la obligación de regular en el reglamento interno de la empresa dicho procedimiento.

92 Artículo 485 del Código del Trabajo. Este artículo enumera en forma taxativa los derechos fundamentales y garantías que tutela: los artículos $19 \mathrm{~N}^{\circ} 1$, inciso primero, siempre que su vulneración sea consecuencia directa de actos ocurridos en la relación laboral; $4^{\circ}, 5^{\circ}$, en lo relativo a la inviolabilidad de toda forma de comunicación privada; $6^{\circ}$, inciso primero, $12^{\circ}$, inciso primero, $16^{\circ}$, en lo relativo a la libertad de trabajo, al derecho a su libre elección y a lo establecido en su inciso cuarto. Así como conoce de los actos discriminatorios a que se refiere el artículo $2^{\circ}$ del Código del Trabajo (a excepción de los contemplados en el inciso sexto referido a las ofertas en el empleo) y las represalias ejercidas en contra de trabajadores en razón o como consecuencia de la labor fiscalizadora de la Dirección del Trabajo o por el ejercicio de acciones judiciales, conocido como "indemnidad".
} 
intimidad y protección de la honra (19 No 4). Asimismo, la situación del mobbing puede traer aparejado la afectación de su derecho a la inviolabilidad de toda forma de comunicación privada (19 No 5), su derecho a no ser discriminada en el caso del mobbing discriminatorio (19 No 16) y su derecho a indemnidad, en caso de haber denunciado su acoso al ente administrativo o judicial y luego obtener represalias por ello.

De lo anterior, se desprende que este procedimiento se dirige solo contra el empleador como legitimario pasivo, exista un mobbing vertical como horizontal ${ }^{93}$. Sin embargo, se observa un vacío respecto a la empresa usuaria en un régimen de servicios transitorios, la cual podría eventualmente resultar responsable en el evento en que se suscite la sanción establecida en el artículo 183-U (fraude a la ley) o 183-N inciso final y ser considerada como empleador para todos los efectos legales. Pese a lo anterior, aun sin que se configuren estos supuestos, y por aplicación de normas de interpretación sistemática, podría considerarse que la empresa usuaria al tener facultades de empleador como el control de la asistencia del trabajador (artículo $183-\mathrm{W}$ ), la organización y dirección del trabajo, y la dictación del reglamento interno que regirá al trabajador (183-X), si tiene responsabilidad de empleador.

El procedimiento de tutela se puede invocar en dos situaciones: a) estando vigente la relación laboral, y b) con ocasión del despido. El plazo para realizar la denuncia -de acuerdo al artículo 486 inciso final del Código del Trabajo- es de 60 días desde que se produce la vulneración de los derechos fundamentales alegada, plazo que se suspende de acuerdo al artículo 168 del Código del Trabajo. Conviene preguntarse si resulta razonable un plazo de 60 días para denunciar un acoso que suele ser difícil de identificar como tal para la víctima.

En el procedimiento de tutela no cabe la acumulación con acciones de otra naturaleza (por ejemplo civiles) o de otras con idéntica pretensión, pero basada en fundamentos diversos (artículo 487). A su vez, si de los mismos hechos emanan dos o más acciones de naturaleza laboral, y una de ellas fuese la de tutela laboral, dichas acciones "deberán ser ejercidas conjuntamente en un mismo juicio, salvo si se tratare de la acción por despido injustificado, indebido o improcedente, la que deberá interponerse subsidiariamente. El no ejercicio de alguna de estas acciones en la forma seńalada importará su renuncia"94. Es decir, se debe tener expreso cuidado en la interposición de las acciones, de lo contrario se podrá estimar que el actor renuncia a sus pretensiones.

El procedimiento de tutela se tramita de acuerdo a las reglas del procedimiento de aplicación general ${ }^{95}$ y tiene preferencia para su vista, desarrollándose en el marco de los principios de inmediación, impulso procesal de oficio y celeridad, entre otros establecidos en los artículos 425 y siguientes del Código del Trabajo.

\subsection{LIMITES A LOS DERECHOS FUNDAMENTALES EN EL PROCEDIMIENTO DE TUTELA}

Con la constitucionalización del derecho laboral y con el reconocimiento de los derechos inespecíficos por los intervinientes del procedimiento laboral, la vulneración de

\footnotetext{
${ }^{23}$ En el mobbing horizontal, se perseguirá a los pares acosạdores a través de la responsabilidad extracontractual en sede ordinaria.

${ }^{44}$ Artículo 489 del Código del Trabajo.

${ }^{95}$ Regulado en los artículos 446 y siguientes del Código del Trabajo.
} 
los derechos fundamentales al interior de la empresa, ya no son tratadas como un "incumplimiento contractual sino como violación de derechos fundamentales, con las consecuencias (...) que ello conlleva" 96 .

En este escenario, el procedimiento de tutela se vislumbra como la gran herramienta que incorpora resguardos a los derechos inespecíficos en sede laboral, ya que incorpora límites concretos al ejercicio de las facultades del empleador.

Frente a la colisión de derechos fundamentales será necesario hacer un examen respecto de la medida vulneratoria: ¡esta tiene justificación suficiente?, ¿es arbitraria o desproporcionada?, ¿se afecta el contenido esencial del derecho vulnerado?

En razón de lo anterior, ante la colisión de derechos fundamentales, deberán ponderarse los límites externos e internos de los derechos fundamentales involucrados, tarea que el artículo 485 del Código del Trabajo consagra expresamente al disponer que:

"Se entenderá que los derechos y garantías a que se refieren los incisos anteriores resultan lesionados cuando el ejercicio de las facultades que la ley le reconoce al empleador limita el pleno ejercicio de aquellas sin justificación suficiente, en forma arbitraria o desproporcionada, o sin respeto a su contenido esencial. En igual sentido se entenderán las represalias ejercidas en contra de trabajadores, en razón o como consecuencia de la labor fiscalizadora de la Dirección del Trabajo o por el ejercicio de acciones judiciales".

\subsection{ALCANCES PROBATORIOS}

El proceso de hostigamiento sistemático puede resultar imperceptible para la víctima en una primera etapa, debido a que el mobbing puede estar encubierto en supuestas bromas, supuestos malentendidos o incluso en el pensarse culpable de la situación. Las diversas formas que puede revestir el mobbing pueden acarrear dificultad en cuanto a la prueba de su existencia.

Una importante novedad que introduce el procedimiento de tutela en el ámbito probatorio, es la incorporación de la "carga alivianada de la prueba". En virtud de la cual se morigera la carga probatoria del afectado en sus derechos fundamentales a través de la técnica de los indicios ${ }^{97}$, ello no implica la radical inversión del onus probandi para el empleador, sino que:

"la víctima o demandante no está completamente liberado de prueba, ya que debe acreditar al menos, la existencia de "indicios" de la existencia de la conducta lesiva, para que recién ahí se traslade al demandado el deber de probar que su conducta se debió a motivos objetivos y razonables (...) por eso se ha dicho con razón que la regla procesal citada, más que alterar la carga probatoria, afecta el objeto de la prueba (thema probandum), ya que el demandante sí debe acreditar un hecho, pero no el que le correspondería según las reglas generales (las conductas discriminatorias

\footnotetext{
${ }^{96}$ Lanata Fuenzalida, Gabriela, Contrato... (n. 38), p. 73.

97 Es decir, señales o evidencias que den cuenta de un hecho oculto (violación de un derecho fundamental). En mensaje No 4-350 22 de septiembre de 2003 de Ley $\mathrm{N}^{\circ} 20.087$.
} 
o lesivas), sino una conducta distinta: la existencia de indicios que hagan verosímil la existencia de la lesión"98.

Una vez acreditados los indicios, será el demandado el que deberá probar, razonablemente, los fundamentos de sus razones distintas de la vulneración de derechos fundamentales. Por tanto, no podríamos considerar que se produce una inversión total de la prueba, pues la víctima deberá acreditar al menos indicios, de lo contrario, se le daría al empleador la obligación de probar hechos negativos.

En este contexto, el juez deberá identificar los derechos fundamentales afectados con el mobbing, y establecer puntos de prueba que permitan determinar los indicios de los cuales se hará valer la víctima así como los fundamentos y la proporcionalidad de las medidas adoptadas por el empleador. La prueba rendida será valorada de acuerdo a la sana crítica ${ }^{99}$.

\subsection{MANIFESTACIONES DE TUTELA INHIBITORIA, RESTITUTORIA Y RESARCITORIA DEL PROCEDIMIENTO DE TUTELA CONTRA EL MOBBING}

Podemos observar diversas manifestaciones de tutela en este procedimiento para poder proteger los derechos fundamentales que se ven vulnerados con la figura del mobbing.

\section{a) Tutela inhibitoria}

Se manifiesta en forma clara con la medida especial consagrada en el artículo 492 del Código del Trabajo, que implica la suspensión de los efectos del acto impugnado en caso de tratarse de lesiones de especial gravedad o si la vulneración denunciada puede causar efectos irreversibles. Esta suspensión se puede obtener en cualquier momento del juicio, lo que facilita la aceleración de la inhibición del acto.

Asimismo, de persistir la vulneración al momento de dictar el fallo, la sentencia debe contener de acuerdo al artículo 495 del Código del Trabajo el cese inmediato de sus efectos.

Otra manifestación de la tutela inhibitoria, consiste en la aplicación de multas al denunciado en la sentencia definitiva.

\section{b) Tutela restitutoria}

Se refleja en la obligación del juez de velar por retrotraer al afectado al estado anterior a la medida vulneratoria, de acuerdo a lo dispuesto en el artículo 495 del Código del Trabajo. Ahora bien, tratándose de un mobbing que se ha producido con ocasión del despido, cabe preguntarse si procede la nulidad del acto de despido en términos tales que permita al afectado recuperar su puesto de trabajo. Sin embargo, el legislador solo contempló dichas consecuencias, tratándose de un despido en el que haya ocurrido una

\footnotetext{
98 Ugarte Cataldo, José Luis, El Nuevo... (n. 11), p. 130.

${ }^{9} \mathrm{El}$ artículo 456 del Código del Trabajo ordena que "Al apreciar las pruebas según la sana crítica, el tribunal deberá expresar las razones jurídicas y las simplemente lógicas, científicas, técnicas o de experiencia en cuya virtud les designe valor o las desestime. En general, tomará en especial consideración la multiplicidad, gravedad, precisión, concordancia y conexión de las pruebas o antecedentes del proceso que utilice, de manera que el examen conduzca lógicamente a la conclusión que convence al sentenciador".
} 
discriminación grave, dado que es el único caso en el que se permite al afectado optar por la indemnización especial contemplada en el procedimiento de tutela o por la reincorporación a sus servicios. En virtud de lo anterior, encontrándonos en una situación de mobbing, solo podríamos invocar este efecto restitutorio en el caso de que ocurra un despido con mobbing discriminatorio grave.

Se debe reconocer de igual forma el gran avance alcanzado con el procedimiento de tutela, pues antes de su incorporación se hacía imperioso contar con un cauce jurídico que permitiera la tutela restitutoria para la persona afectada en sus derechos fundamentales:

"Una vez probado el acto lesivo de los derechos fundamentales del trabajador, surge de inmediato el problema de su sanción jurídica, y de ahí la solución no parece admitir duda: dichos actos son nulos, simplemente porque lesionan derechos contemplados en normas de superior rango jurídico como son las constitucionales, lo que habilitaría para que cualquier órgano judicial que conociere de dicha situación los declare como tales(...) sin embargo, entendido que la más que predecible inhibición con que nuestros tribunales operan en esta materia, discutiblemente explicada por la falta de un procedimiento especial de nulidad laboral, ni de disposición legal del Código del Trabajo que autorice dicha declaración (según el dogma de que no hay nulidad sin texto expreso), se hace absolutamente necesario, para la configuración de una protección mínimamente aceptable de los derechos fundamentales en el ámbito del trabajo, de una recepción expresa de la nulidad radical del acto lesivo de los derechos fundamentales" 100 .

Queda pendiente extender los efectos de la nulidad, concretizados por ejemplo en la posibilidad de reincorporación del actor despedido con ocasión del despido, para el resto de los casos, como se presente una situación de mobbing, "la nulidad es una consecuencia lógica de la estructura del acto abusivo... "lo importante para la sociedad es sancionar con el máximo rigor posible al injurioso, una consecuencia de peso es privar a la conducta abusivo del logro de sus fines"101.

\section{c) Tutela resarcitoria}

Conviene distinguir dos situaciones para su análisis: el caso del mobbing que ha sido denunciado estando vigente la relación laboral, como en el mobbing que es denunciado con ocasión del despido. En el primer caso, la persona vulnerada en sus derechos podrá solicitar indemnización por daño moral por los daños extrapatrimoniales provocados por el acoso.

Y tratándose del procedimiento de tutela invocado con ocasión del despido, se contempla en el artículo 489 del Código del Trabajo una indemnización especial de seis a once remuneraciones, dentro de la cual se encontraría por razones de seguridad jurídica ya contemplado el resarcimiento del daño moral ${ }^{102}$.

\footnotetext{
100 Ugarte Cataldo, José Luis, El Nuevo... (n. 11), pp. 136-137.

101 CAPÓN FILAS, Rodolfo E., "El abuso del derecho en relación al contrato de trabajo", en: Estudios sobre Derecho Individual de Trabajo en homenaje al profesor Mario L Devali, Editorial Heliasta, Buenos Aires, p. 768.

102 En este sentido Gamonal CONTReras, Sergio; Prado LÓPEZ, Pamela, El mobbing... (n. 20).
} 
Destaca también como manifestación de tutela resarcitoria, lo dispuesto en el artículo 495 del Código del Trabajo referido a que el juez debe ordenar en la sentencia que acoge una procedimiento de tutela, la incorporación de medidas concretas que el infractor debe realizar para obtener la reparación de las consecuencias provocadas por su acto lesivo. Por ejemplo, la juez del caso del Colegio Alemán determinó respecto de un despido discriminatorio, que:

"La Corporación del Colegio Alemán de Valparaíso, vencida deberá, además, dentro de un plazo no superior a dos meses, contados desde que la presente sentencia adquiera el carácter de ejecutoriada, realizar en su establecimiento, como actividad extra-programática, una jornada especial de reflexión sobre el tema de discriminación y a la que deberá convocar a todos los miembros de la comunidad escolar, incluyendo padres y apoderados, profesores, personal no docente y alumnos".

Asimismo, en el caso la "teleoperadora de religión musulmana" dictado recientemente $^{103}$, la sentenciadora, tras tener convicción de la vulneración del derecho a la no discriminación por razones de religión, ordenó asignarle un nuevo supervisor a la trabajadora afecta$\mathrm{da}$, publicar disculpas públicas a la afectada dentro de la empresa y en las liquidaciones del mes siguiente de todos los trabajadores de esta, realizar una capacitación no inferior a seis horas cronológicas para la totalidad de los empleados, para fomentar el trato adecuado y respeto dentro de la empresa, y comunicar la resolución recaída en el procedimiento de tutela a la empresa principal para la cual se prestan sus servicios de contratista.

\section{CONSIDERACIONES FINALES}

El procedimiento de tutela ha venido a ser el gran cauce jurídico para enfrentar una situación de mobbing, estando vigente la relación laboral como con ocasión del despido. Con anterioridad al establecimiento de este procedimiento, se observaban mecanismos procesales que no eran del todo efectivos en el ámbito de la tutela inhibitoria, restitutoria y resarcitoria de los derechos fundamentales afectados con el mobbing.

Las normas que inspiran el procedimiento de tutela se encuentran en sintonía con el reconocimiento de los derechos inespecíficos al interior de la empresa, con la eficacia horizontal de los mismos.

Las medidas de inhibición contempladas en este procedimiento, se plantean eficaces al contemplar el cese inmediato de las conductas lesivas, así como el pago de multas, hasta que las mismas queden sin efecto.

Se observan importantes facultades del juez en este procedimiento, para que el trabajador afectado vuelva al estado anterior del acoso. Si bien se observan materias que se pueden mejorar en esta línea, es destacable el avance de la tutela restitutoria actual introducida con este procedimiento. Asimismo, este procedimiento contempla en sede laboral, la posibilidad de resarcimiento del daño moral de la víctima, evitando trámites posteriores y dilaciones para el trabajador que tiene derecho a la misma.

${ }^{103}$ Causa Rit T-38-2010, caratulada "Melo con TP Chile S.A." tramitada ante el Primer Juzgado de Letras del Trabajo de Santiago. 
Es de gran ayuda para el esclarecimiento de la vulneración de los derechos fundamentales, la morigeración de la carga de la prueba del denunciante, a través de la prueba indiciaria. Sin embargo, conviene precaverse de toda la prueba posible una vez identificados los derechos fundamentales afectados con el mobbing, puesto que frente a los indicios suficientes de la vulneración de derechos estará la posibilidad del denunciado de acreditar la razonabilidad y proporcionalidad de sus medidas.

No siempre resulta explícita o identificable la vulneración de derechos fundamentales en el caso del mobbing. La solicitud de fiscalizaciones a la Inspección del Trabajo, los certificados e informes médicos y la prueba testimonial pueden volverse determinante en un procedimiento de tutela.

Por último, de las normas que contempla la legislación para regular los derechos fundamentales involucrados afectados con la figura del mobbing, se observa la ausencia de mecanismos de prevención del mismo. Es por ello que se torna fundamental, hasta que se regularice la situación a través de la legislación, el establecer medidas preventivas que sean convenidas por las partes de la relación laboral por ejemplo en convenios colectivos, y el promover una cultura dentro de la empresa de respeto a todos los intervinientes del proceso productivo. Así se evitarán situaciones como las descritas en el caso de mobbing discriminatorio en el ejemplo de la "teleoperadora de religión musulmana":

"Me he sentido menoscabada, vejada en lo más íntimo de mi integridad, me he sentido tan mal, que incluso tengo ganas de irme de Chile. No he dormido, tenía pesadillas, tuve que empezar a tomar pastillas para dormir, busqué psiquiatras, hasta que encontré uno que me ha ayudado, también ha afectado en mi familia, incluso mi hijo ha bajado las notas, porque he estado muy mal, he tenido que estar con licencias en periodos largos. Lo que ha pasado no es una cuestión de dinero, sino que una cosa de respeto" 104 .

\section{BIBLIOGRAFÍA}

Abajo Olivares, Francisco Javier, Acoso psicológico en el ámbito laboral, LexisNexis-DePalma, Buenos Aires, 2004, 612 pp.

Canabellas de Torres, Guillermo; Alcalá Zamora y Castillo, Luis, Tratado de Política Laboral y Social, tomo II, tercera edición, Editorial Heliasta, Buenos Aires, 1964, 675 pp.

CAAMAÑo Rojo, Eduardo, "La ley de subcontratación y la tutela de los derechos fundamentales de los trabajadores de servicios transitorios", en: Ius et Praxis [online]. 2007, vol. 13, No 2, Talca, pp. $157-$ 194 [citado 2010-02-22]. Dsponible en: <http://www.scielo.cl/scielo.php?script=sci_arttext\&pid= S071800122007000200008\&lng=es\&nrm=iso>. ISSN 0718-0012. doi: 10.4067/S071800122007000200008 .

CaAmaño Rojo, Eduardo, Carvajal Godoy; Gabriela, Jiménez Trejo, Patricio, El Acoso Sexual en la empresa. Análisis de la Ley 20.005, Santiago, 2005.

${ }^{104}$ Nora Melo en sentencia de fecha 26 de abril de 2010, de causa Rit T-38-2010, caratulada "Melo con TP Chile S.A." tramirada ante el Primer Juzgado de Letras del Trabajo de Santiago. 
CAPON FILAS, Rodolfo E., "El abuso del derecho en relación al contrato de trabajo", en: Estudios sobre Derecho Individual de Trabajo en homenaje al profesor Mario L. Devali, Editorial Heliasta, Buenos Aires, pp. $759-789$.

Gamonal Contreras, Sergio, El Procedimiento de tutela de los derechos laborales, primera edición, Editorial LexisNexis, Santiago, 2007, 78 pp.

Gamonal Contreras, Sergio, Guidi Moggia, Caterina, Manual del Contrato de Trabajo, primera edición, Editorial AbeledoPerrot-LegalPublishing, Santiago, 2010, 329 pp.

Gamonal Contreras, Sergio, Prado LÓpz, Pamela, El mobbing o acoso moral laboral, Editorial LexisNexis, Santiago, 2009, 154 pp.

Gamonal Contreras, Sergio y Walker ErRazUriz, Francisco, "Informe nacional de Chile, tema III", en: VIII Congreso Regional Americano de Derecho del Trabajo y la Seguridad Social y XXVIII Congreso Nacional de Derecho del Trabajo y la Seguridad Social de Colombia, Cartagena de Indias, mayo 25 al 28, 2010, No 684 de 06/02/1997.

LANATA Fuenzalida, Gabriela, Contrato individual de trabajo, tercera edición, Editorial LegalPublishing, Santiago, 2009, $410 \mathrm{pp}$.

lizama Portal, Luis y Ugarte Cataldo, José Luis, Nueva Ley de Acoso Sexual, primera edición, Editorial LexisNexis, Santiago, 2005, 129 pp.

Lizama PORTAL, Luis y UgaRTe CATAldo, José Luis, Interpretación y Derechos Fundamentales en la Empresa, Editorial ConoSur Ltda., Santiago, 1998.

LÓPEZ, Diego, "Los derechos fundamentales en el trabajo: garantía de libertad y dignidad de las personas que trabajan", en: Temas Laborales de la Dirección del Trabajo 22, noviembre 2004. Disponible en: <http://

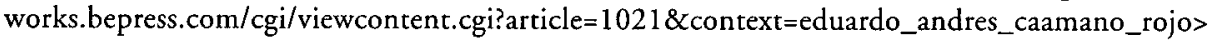

MAZZo ITURRIAGA, Rodrigo, “De qué se habla: mobbing”, Santiago, 2009, en: < http://www.bcn.cl/de-quese-habla/mobbing-acoso-chiles

MELIS, Christian, "Derechos fundamentales y empresas: apuntes para una configuración dogmático-jurídica", en: Anuario de Derecho del Trabajo y Seguridad Social $N^{\circ}$. 3/2004, Derechos Fundamentales. Homenaje al Profesor Patricio Novoa Fuenzalida, Sociedad Chilena de Derecho del Trabajo y de la Seguridad Social, Santiago, pp. 71-115.

NogueIra AlCalá, Humberto, Dogmática Constitucional, Editorial Universitaria de Talca, Talca, 1997.

Palavecino Cáceres, Claudio, "La Protección Contra el Acoso Psíquico Laboral en el Ordenamiento Jurídico Chileno", en: Revista de Derecho, Valdivia [online]. 2004, vol. 17 [citado 2010-02-22], pp. 63-89. Disponible en:<http://www.scielo.cl/scielo.php?script=sci_arttext\&pid=S071809502004000200003 \&lng=es\&nrm=iso>. ISSN 0718-0950. doi: 10.4067/S0718-09502004000200003

PalOMEQUe López, Manuel Carlos, Los Derechos laborales en la Constitución española, Centro de Estudios Constitucionales, Madrid, 1991.

Plá RodrígueZ, Américo, Curso de Derecho laboral, Ediciones Idea, Uruguay, 1991, 285 pp.

PINUUEL Y ZABALA, Iñaki, "El Mobbing aumenta entre los funcionariös", Madrid, 2008, disponible en: < http:// acosopsicologico.blogspot.com/2008_09_01_archive.html>

Ugarte Cataldo, José Luis, El Nuevo Derecho del Trabajo, primera edición, Editorial Universitaria, Santiago, 2004, 183 pp.

Ugarte Cataldo, José Luis, Tutela de Derechos fundamentales del trabajador, Editorial Legal Publishing, Santiago, 2009, $102 \mathrm{pp}$.

WALKER ERRAZURIZ, Francisco, Derecho de las relaciones laborales, primera edición, Editorial Universitaria, Santiago, Chile, 2003, 718 pp. 
Lucía Planet Sepúlveda / Eficacia del procedimiento de tutela laboral como protección contra el mobbing en Chile

\section{SITIOS WEB CONSULTADOS}

ACOSO MORAL. ORG [en línea] <www.acosomoral.org>

BASE DE DATOS PUNTOLEX LEYES Y SENTENCIAS [en línea] <http://www.puntolex.cl/prod_lys/575/ channel.html>

DIRECCION DEL TRABAJO [en línea] <www.dt.gob.cl>

ESTUDIO DE LA SOCIEDAD VALENCIANA DE MEDICINA Y SEGURIDAD EN EL TRABAJO [en línea] www.symst.com

PODER JUDICIAL, CONSULTA DE CAUSAS LABORALES [en línea] http:// laboral.poderjudicial.cl:9081/SITLAPORWEB/InicioAplicacionPortal.do

MOBBING OPINION [en línea] <http://mobbingopinion.bpweb.net/>

SENADO SITIO OFICIAL [en línea] <http://sil.senado.cl/pags/index.html>

WORD REFERENCE [en línea] <www.wordreference.com> 